(Medicinische Klinik in Greifswald.)

\title{
Ueber die Zuckerbildung im Organismus beim Pankreasdiabetes.
}

\author{
Zugleich eine Entgegnung auf die wiederholten Angriffe \\ von Eduard Pflüger. \\ Von
}

\section{o. Minkowski.}

Als ich im Jahre 1889 in Gemeinschaft mit v. Mering die Beobachtung machte, dass nach der vollständigen Exstirpation des Pankreas bei Hunden ausnahmslos ein schwerer, bis zum Tode andauernder Diabetes auftritt, war es uns von vorne herein klar, dass die Bedeutung dieser Beobachtung nicht in der gefundenen Thatsache allein $z u$ suchen war. Wir erblickten vielmehr in der experimentellen Ausschaltung des Pankreas ein Mittel, welches es ermöglichte, willkürlich eine Krankheit zu erzeugen, die dem menschlichen Diabetes ähnlicher war als irgend eine der früher bekannten experimentell zu erzeugenden Glykosurien. Durch die weitere Verfolgung der von uns gefundenen Thatsache hofften wir nicht nur über diese räthselhafte Stoffwechselkrankheit Aufklärung zu erhalten, sondern auch einen Einblick in manche Vorgänge des thierischen Organismus zu gewinnen, die mit dem Zuckerstoffwechsel in inniger Beziehung stehen.

Wir betraten mit unseren Untersuchungen ein vollkommen neues Gebiet. Wir gingen daher voraussetzungslos an unsere Versuche heran und bemühten uns, aus unseren Beobachtungen die Antworten auf die nächstliegenden Fragen abzuleiten. Als eine der wichtigsten erschien uns von Anfang an die Frage, ob, und gegebenenfalls in welchem Umfange, Kohlehydrate aus anderen Substanzen im Organismus gebildet werden können. Denn diese Frage war nicht nur an und für sich von besonderem Interesse, 
ihre Beantwortung war auch die unerlässliche Vorbedingung für eine Beurtheilung aller übrigen Vorgänge des Zuckerstoffwechsels.

Gleich die ersten Versuche ${ }^{1}$ ) ergaben, dass die Hunde nach der Entfernung der Bauchspeicheldrüse bei reiner Fleischkost so grosse Zuckermengen im Harne entleerten, dass diese unmöglich allein aus den mit der Nahrung eingeführten präformirten Kohlehydraten abgeleitet werden konnten. Es zeigte sich überdies, dass der im Organismus in Form von Glykogen abgelagerte Kohlehydratvorrath nach dem Auftreten des Diabetes in Folge der Totalexstirpation des Pankreas stets in wenigen Tagen nahezu ersehöpft war, während die Zuckerausscheidung noch in erheblichem Maasse fortdauerte. Somit ging aus unseren Beobachtungen zunächst hervor, dass im thierischen Organismus auch aus anderen Atomcomplexen Zueker gebildet werden kann. Auf eine Entstehung des Zuckers aus den Ei w e is substanzen schien es hinzudeuten, dass bei ausschliesslicher Fleichnahrung die Menge des im Harne ausgeschierlenen Zuckers in gewissen Beziehungen zu der ausgeschiedenen Stickstoffmenge stand.

Diesen Beziehungen zwischen der Zuckerausscheidung und der Stickstoffausfuhr habe ich dann auch später, als ich die Untersuchungen über den Parkreasdiabetes ${ }^{\circ}$ ) allein weiter fortsetzte, eine besondere Aufmerksamkeit zugewandt. Durch zablreiche Beobachtungen, die sich auf einen Zeitraum von vier Jahren vertheilten, gewann jch die Ueberzeugung, dass das Verhältniss der Dextrose zum Stickstoff im Harne der diabetisehen Thiere sich in der That unter gewissen Bedingungen innerhalb sehr enger Grenzen bewegte. Es zeigte sich hierin eine Abhängigkeit der Zuckerbildung vom Eiweissumsatze, deren einfachste Erklärung die Annahme war, dass der im Organismus gebildete Zucker direct den zersetzten Eiweisssubstanzen seinen Ursprung verdanke. Meine Beobachtungen wurden daher vielfach auch als eine wesentliche Stütze für die Annahme einer Zuckerbildung aus Eiweiss angeseben, um so mehr als eine solche ohnehin auf Grund von zahlreichen früheren experimentellen und namentlich auch klinischen Erfahrungen den meisten Autoren als sehr wahrscheinlich galt.

Nur Wenige, und zu diesen gehörte in erster Reihe Fduard

1) Arch. f. exper. Pathol, u. Pharmakol. Bd. 26. 1889.

2) Minkowski, Untersuchungen über den Diabetes mellitus nach Exstirpation des Pankreas. Leipzig 1893. - Arch. f. exper. Pathol. u. Pharmakol. Bd. 31. 
Pflüger, glaubten nach wie vor die Zuckerbildung aus Eiweiss nicht anerkennen zu dürfen. In sehr eingehender Weise suchte Pfl üg e r ${ }^{1}$ ) nachzuweisen, dass bei fast allen Versuchen, welche die Zuckerbildung aus Eiweiss beweisen sollten, auf den Kohlehydratvorrath des Organismus nicht genügend Rücksicht genommen war, da dieser unter Benutzung einer von Pflüger ausgearbeiteten Methode erheblich grössere Werthe aufwies, als sie durch die früher üblichen Methoden ermittelt werden konnten.

Auf meine Versuche über den Pankreasdiabetes war Pflüger in der ersten Auflage seines Werkes zunächst gar nicht näher eingegangen. Ich nehme an, dass dieses hauptsächlich desshalb geschah, weil Pflüger damals noch nicht Gelegenheit gehabt hatte, eigene Beobachtungen über die Folgen der Pankreasexstirpation anzustellen, und daher noch nicht davon überzeugt war, dass gegenüber den Erfahrungen über den Pankreasdiabetes seine Berechnungen versagen mussten.

Es wäre mir ein Leichtes gewesen nachzuweisen, dass die Voraussetzungen Pflüger's in ihrer Anwendung auf die von mir publicirten Versuche zu so unwahrscheinlichen Annahmen führen mussten, dass diese ernstlich überhaupt nicht in Frage kommen konnten. Es erschien mir aber als eine unproductive Arbeit, dieses durch Discussionen allein beweisen zu wollen, un so mehr als es für mich auch keinem Zweifel unterlag, dass eine Wiederholung meiner Versuche unter solchen Modificationen, die sie auch für Pflüger einwandfrei erscheinen lassen mussten, nur zu den gleichen Resultaten führen konnte. Aeussere Verbältnisse machten es mir damals schwer, diese Untersuchungen sogleich in Angriff zu mehmen, und ich begrüsste

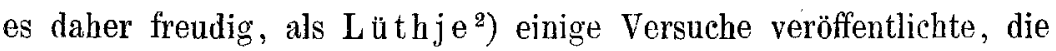
im Wesentlichen eine Bestätigung meiner Beobachtungen brachten und "so ausgeführt waren, wie es die Pflüger'sche Kritik verlangte". Diese Versuche Lüthje's überzeugten auch Pflüger davon, dass „Kohlehydrate im Organismus aus Substanzen entstehen, die keine Kohlehydrate sind". Auch Lüthje fand, dass bei Ausschluss von Kohlehydraten aus der Nahrung mit der Grösse des Eiweissumsatzes auch die Grösse der Zuckerausscheidung stieg, und

1) E. Pflüger, Das Glykogen. Erste Auflage. Bonn 1903.

2) Hugo Lüthje, Die Zuckerbildung aus Eiweiss. Deutsch. Arch f. klin. Medic. Bd. 79 S. 488. 1904. 
auch ihm schien „der Parallelismus zwischen der Grösse der Zuckerausscheidung und der Grösse des Stickstoffumsatzes in dem Sinne zu sprechen, dass $z$ wischen beiden genetische Beziehungen vorhanden sind".

Dieser letzteren Schlussfolgerung glaubt $\mathrm{Pfl}$ üg er ${ }^{1}$ ) sich auch jetzt noch nicht anschliessen zu dürfen, obgleich er selbst „in viel ausgedehnterem Maasse als H. Lü thje diese Entdeckung bestätigen konnte", nämlich, dass „beim Pankreasdiabetes die Zufubr von Eiweiss unzweifelhaft die Ausscheidung des Zuckers auch dann steigert, wenn keine Kohlehydrate neben dem Eiweisse gereicht wurden oder als Reservestoffe in Betracht gezogen werden können". Pfilüger hält auch jetzt noch die Zuckerbildung aus $\mathrm{Eiweiss}$ für unwabrscheinlich. Er glaubt vielmehr in dem Fette die Quelle des Zuckers suchen zu müssen, und beschäftigt sich sehr eingehend mit den chemischen Processen, die der Umwandlung des Fettes in Zucker zu Grunde liegen könnten. Um den - jetzt auch für ihn zweifellosen - Einfluss des Stickstoffumsatzes auf die Zuckerbildung zu erklären, weist er auf die Möglichkeit hin, dass „bei der Oxydation des Eiweisses im Pankreasdiabetes jedes Stickstoffatom in statu nascendi ein Sauerstoffatom auf die Methylengruppe $\mathrm{CH}_{2}$ der Fette zu übertragen hat, um sie in $\mathrm{COH}_{2}$ überzuführen". Auf diese Hypothese werden wir noch zurückzukommen haben.

Die von mir behauptete Abhängigkeit der Zuckerbildung vom Eiweissumsatze beim Pankreasdiabetes hat somit sowohl durch Lüthje wie durch Pflüger eine Bestätigung erfahren, wie denn überhaupt - wie ich hier zu zeigen hoffe - jede einzige von mir behauptete Thatsache, wie von Anderen, so auch von Pflüger selbst bis jetzt nur in vollem Umfange bestätigt worden ist. Blos in der Deutung der Erscheinungen stimmen Pflüger und ich nicht überein.

Eine solche Divergenz der Ansichten ist in wissenschaftlichen Fragen gewiss nichts Seltenes. Sie kann der Erkenntniss nur förderlich sein, insofern sie zu neuen Untersuchungen und neuen Fragestellungen Anregung giebt. Und wenn ein so temperamentvoller Autor, wie Pflüger es nun einmal ist, gelegentlich auch im Eifer

1) E. Pflüger, Ein Beitrag zur Frage nach dem Ursprung des im Pankreasdiabetes ausgeschiedenen Zuckers. Pflüg er's Arch. Bd. 108 S. 146.1905. 
der Discussion selbst die Urtheilsfähigkeit Desjenigen bemängelt bätte, der die Dinge anders ansieht als er selbst, so wäre ich der Letzte, der sich darüber entrüstet hätte!

In einer für mich unbegreiflichen Weise hat aber Pflüger, seitdem er sich selbst mit dem Pankreasdiabetes beschäftigt und in die Lage gekommen ist, auch meine Untersuchungen genauer besprechen zu müssen, sich veranlasst gesehen, immer heftigere Angriffe gegen mich zu richten ${ }^{\mathbf{1}}$ ). Obwohl er, wie gesagt, thatsächlich keine einzige Beobachtung gemacht hat, die mit meinen Angaben in Widerspruch stünde, glaubte er wiederholt meine Zuverlässigkeit und meine Wahrheitsliebe anzweifeln zu müssen. Dagegen musste ich Einspruch erheben!

Ich begnügte mich damit, darauf hinzuweisen ${ }^{2}$ ), dass den Ângriffen Pflüger's nur unzutreffende Schlussfolgerungen und missverständliche Aufassungen meiner Behauptungen zu Grunde lagen. Für Beides führte ich Beispiele an, um damit die Forderung zu begründen, „über die Anschauungen anderer Autoren nach den Angaben Pflüger's erst dann zu urtheilen, wenn man diese mit den Originalarbeiten verglichen hat". Durch diese Forderung glaubte ich der Nothwendigkeit überhoben zu sein, alles das erschöpfend vorzubringen, was ich gegen Pflüger's Angriffe geltend zu machen hatte. Mein Stillschweigen über andere Vorwürfe, die Pflüger gegen mich erhohen hatte, sollte keineswegs bedenten, dass ich diese Vorwürfe als berechtigt anerkannte. Zum Schluss wies ich noch darauf hin, dass P fl üger die Arbeiten anderer Autoren auch dann noch zu ignoriren sich für berechtigt hält, wenn er selbst zu den gleichen Resultaten gelangt ist. Auch hierfür führte ich ein Beispiel ${ }^{3}$ ) an.

1) Siehe Eduard Pflüger, Das Glykogen. Zweite Auflage. Bonn 1905.

2) Minkowski, Bernerkungen über den Pankreasdiabetes. Zur Abwehr gegen Eduard Pflüger. Arch. f. exper. Pathol. u. Pharm. Bd. 53 S. 331.1905.

3) Es handelte sich um die Dissertation von Abelmann, die mit den hier besprochenen Fragen keinen directen Zusammenhang hat, und auf welche ich hier näher einzugehen eigentlich keine Veranlassung habe. Da mir indessen Pf] ü ger gerade in diesem Punkte einen besonders schweren Vorwurf macht, so sehe ich mich genöthigt, auch diesen Gegenstand noch einmal zu berühren: Pflüger weist darauf hin, dass er die Arbeit von Abelmann schon früher einmal abfällig kritisirt bätte, dass es daher „ein Beispiel von der fast unglaublichen Oberflächlichkeit" von mir sei, wenn ich ihm die Unkenjtniss dieser

E. Pflüger, Archiv für Physiologie. Bd. 111* 
Auf diesen meinen Einspruch, bei welchem ich nur sachliche Interessen verfolgte und jeden persönlich beleidigenden Ausdruck auf das Peinlichste zu vermeiden suchte, hat nun $P$ flüge ${ }^{1}$ ) mit neuen Angriffen geantwortet, indem er mir nichts weniger als „die gröbsten Irrthumer", „absolut unwahre Behauptungen“, „erstaunlichen Mangel an gewissenhafter Prüfung", "unglaubliche Oberflächlichkeit" u. dergl. mehr vorwirft.

Angriffen dieser Art gegenüber würde ich, wenn ich meinem subjectiven Empfinden folgte, in der That am liebsten "mäuschenstill" geschwiegen haben! Ich glaube, dass Diejenigen, die meine Arbeiten kennen, auch das als „beredtes Schweigen“ gedeutet bätten! Im Interesse der Sache aber, im Interesse der Anschaunngen, die ich vertrete, halte ich mich für verpflichtet, da ich durchaus in der Lage bin, Pflüger's Vorwürfe mit guten Gründen zurückzuweisen, diese Gründe auch öffentlich vorzubringen. Ich weiss sehr wohl, wie unerquicklich derartige persönliche Auseinandersetzungen sind. Aber ich will versuchen, sie dadurch zu mildern, dass ich mich bemühe, auch zur sachlichen Klärung der in Rede stehenden Fragen etwas beizutragen.

Ich darf hier meinem aufrichtigen Bedauern darüber Ausdruck

Arbeit vorgeworfen bätte. Sollte ich wirklich angenommen baben, dass Pflüger die Arbeit Abelmann's nicht gekannt hat, als ich meinte, dass er eigentlich diese Arbeit „hätte kennen müssen“? Ich hatte doch nur eine mildere Form gewählt, um das auszudrücken, was $\mathrm{P}$ fl ü ger jetzt selbst zugiebt: dass er die Arbeit nicht hat kennen wollen! Ich wies auf die Sandmeyer'sche Arbeit hin, in der die Untersuchungen Abelmann's eingehend besprochen werden, um zu zeigen, dass diese Untersuchungen Pflüger nicht bätten entgehen sollen. Es lag mir dies besonders nahe, weil $P$ flüger sich jetzt gerade auf $S$ andmeyer bezogen hatte. Gewiss bätte ich ebensogut die frähere Kritik Pflüger's anführen können, um zu beweisen, dass ihm die Arbeit Abelmann's bekannt sein musste. In jener Kritil hat zwar Pflüger die Angaben Abelmann's, meiner Ansicht nach, nicht widerlegt, aher er hat erklärt, dass er nicht an sie glaube, dass er "hundert Mal lieber an Versuchsfebler glaube"! Nun, eine Arbeit, an die man nicht glaubt, mag man vielleicht ignoriren, wenn man selbst zu entgegengesetzten Resultaten gelangt ist. Aber ich betonte ja gerade, dass Pflüger jetzt die gleiche Beobachtung gemacht hat, die Abelmann schon vor 15 Jahren veröffentlicht hat. In solchem Falle hätte Pflüger doch wohl A belmann schon nennen dürfen!

1) Pflüger, Professor O. Minkowski's Abwehr gegen meine ihn treffende Kritik. Pf]üger's Arch. Bd. 110. 12. Oct. 1905. 
geben, dass gerade Pflüger mir in diesen Fragen mit einer Erbitterung entgegengetreten ist, die es ihm unmöglich macht, meine Arbeiten ohne Voreingenommenheit zu lesen, und ihn in Folge dessen dazu führt, mich immer wieder misszuverstehen und mir Ansichten zuzuschreiben, die ich niemals vertreten habe. Ich bedaure dieses um so mehr, als ich meinerseits nicht nur in den thatsächlichen Beobachtungen Pflüger's eine willkommene Bestätigung meiner Angaben erblicken muss, sondern auch in seinen Betrachtungen und Erwägungen neben Manchem, dem ich widersprechen zu müssen glaube, auch Vieles finde, was zur Klärung der strittigen Fragen dienen kann und wesentliche Fortschritte unserer Erkenntniss anzubahnen geeignet ist. Ich hoffe hier zeigen zu können, dass, wenn man nicht hartnäckig an Schlagworten festhalten will, sondern sich erustlich bemüht, den Dingen auf den Grund zu gehen, auch für scheinbar diametral entgegengesetzte Anschauungen sich ein Weg der Verständigung finden lässt, ohne dass man genöthigt wäre, den Andersdenkenden zu verunglimpfen.

Dass Pflüger mir thatsächlich „Ansichten zugeschrieben hat, die genau das Gegentheil von dem darstellen, was ich behauptet habe", dafür habe ich in meiner "Abwehr" ein schlagendes Beispiel angeführt. Pflüger giebt hier das Missverständniss zu, aber er meint: „Die Unklarheit von O. Minkowski's Darstellung ist also die Ursache, wenn ich seinen Worten einen Sinn beilegte, der zwar wohl der Wahrheit entspricht, aber nicht mit der Meinung o. Mink owski's übereinstimmt."

Ich will diesen Vorwurf der "Unklarheit der Darstellung " gelten lassen, obgleich ich mir die Abfassung meiner Veröffentlichungen nicht leicht zu machen pflege und mich nach Kräften redlich bemühe, möglichst klar zu sein. Aber auch auf Kürze und Knappheit der Darstellung glaubte ich bisher in Interesse der Leser meiner Arbeiten Werth legen zu müssen. Diese Kürze war vielleicht daran Schuld, dass meine Aeusserungen bisweilen nicht nur von Pflüg er, sondern auch von Anderen missverstanden wurden. Daher suche ich dieses Mal mich einer grösseren Klarheit, selbst auf Kosten der Kürze, zu befleissigen.

Um nicht wieder der Verschweigung von wesentlichen Momenten geziehen zu werden, will ich mich Punkt für Punkt an den letzten Artikel von $\mathrm{Pfl}$ üger halten: 
Pflüger weist in dieser seiner "Antwort" zuerst meine Bemerkung als "ungehörig" zurück: „Pflüger liebt es bekanntlich, in seinen Arbeiten die Untersuchungen anderer Autoren einer strengen Kritik zu unterziehen." Er betont, dass er in seinem Werke über das Glykogen die Pflicht hatte, Kritik zu üben.

Nun, nicht d ass er Kritik geubbt, sondern wie er diese Kritik geübt, habe ich ihm zum Vorwurf gemacht! Dass Pflüger mit Vorliebe die Untersuchungen anderer Autoren einer strengen und nicht immer wohlwollenden - Kritik zu unterziehen pflegt, wer wollte das leugnen, der die Werke seines arbeitsreichen Lebens kennt? Wer zählt die Autoren, an deren Veröffentlichungen Pflüger schon Kritik geübt! Es sind Namen von gutem Klange darunter, und ich befinde mich nicht in schlechter Gemeinschaft. Darüber hätte ich mich nicht beklagt! Aber dass die Kritik sich auf unzutreffende Angaben gründete, das war es, was mich zur Abwehr nöthigte!

Den besten Beweis für diese meine Behauptung bringt Pflüger jetzt selbst, indem er meine Bemerkung auch als "verwegen" hezeichnet, weil sie ihn zwinge zu zeigen, dass seine Kritik gerarle gegen mich "von absoluter Nothwendigkeit war, weil sie die gröbsten Irrthümer aufdeckte, die bei der Forsehung über Glykosurie nur begangen werden können".

Wenn Pflüger mir einen Irrthum nachgewiesen hätte - ich hätte mich dessen wahrlich nicht geschämt! „Nur Der ist vor Irrthum sicher, der überhaupt nicht arbeitet!" schrieb mir einst der verstorbene H. Huppert. Ueberdies: es ist doch Pflüger, der meine Versuche einer Nachprüfung unterzicht, und nicht ich bin es, der die seinen wiederholt! Der Nachfolgende hat es immerhin etwas leichter, den richtigen Weg zu finden als der Vorangehende:

Aber hat mir denn Pflüger wirklich einen Irrthum, und gar einen der gröbsten, nachgewiesen?

Pflüger sagt: „Wer sollte es für möglich halten, dass ein Forscher wie 0. Min kow ski ... ausserordentlich oft Glykosurie, d. h. Zucker im Harne diagnosticirt hat, wo weder Glykosurie noch Zncker vorhanden war." Ich frage: Wann und wo soll das geschehen sein? Pflüger citirt meine Bemerkung: "zwar beobachtet man, wi e bekannt, solche vorübergehende Glykosurien nach allen mögJichen, länger dauernden chirurgisehen Operationen u. s. w." $\mathrm{Er}$ 
habe aber im Verein mit Wenzel und Schöndorff "bei 144 Patienten nach schweren chirurgischen Operationen festgestellt, dass die Harne zwar stärker reducirten, aber keine Spur von Zucker enthielten". Ich habe noch nie Veranlassung gehabt, an der Richtigkeit einer von $\mathrm{Pfl}$ üg er gemachten thatsächlichen Angabe zu zweifeln. Ich will also, trotz der soeben von Salkowskil) gegen die Pflüg er'sche Methodik des Zuckernachweises erhobenen und, wie es scheint, nicht unbegründeten Einwände, gerne glauben, dass keiner von diesen 144 Operirten Zucker im Harne ausgeschieden hat. Aber man könnte doch vielleicht darüber verschiedener Ansicht sein, ob damit nun wirklich bewiesen ist, dass nach schweren chirurgischen Operationen Zucker im Harne niemals auftreten kanu. Denn es existiren auch aus neuerer Zeit noch gegentheilige Beobachtungen ${ }^{2}$ ). Doch gesetzt den Fall, Pflüger hätte wirklich bewiesen, dass alle diese Beobachtungen aus älterer und neuerer Zeit fehlerhaft wären — was würde dann für ein Vorwurf für mich daraus zu folgern sein? Dass ich im Jahre 1893 noch nicht wusste, die damals allgemein verbreitete Ansicht $^{3}$ ) würde im Jahre 1904 durch Pflüg er widerlegt werden! Habe ich denn von meinen eigenen Erfahrungen bei „allen möglichen chirurgischen Operationen" gesprochen? Oder tritt etwa nach der Pankreasexstirpation kein Zucker im Harne auf? Ich habe doch jene vorübergehenden Glykosurien nach operativen Eingriffen nur erwähnt, um zu zeigen, dass der Pankreasdiabetes mit solchen Glykosurien nicht zu identificiren ist. Hatten sich die Autoren, deren Beobachtungen ich als "bekannt" voraussetzte, geirrt, -- um so mehr durfte die Glykosurie nach der Pankreasexstirpation als etwas Besonderes gelten!

Dann hält mir Pflüger vor, dass ich diese „falsche“ Annahme einer traumatischen Entstehung für die von mir nach der Exstirpation der Speicheldrüsen beobachtete vorübergehende Glykosurie als Erklärung habe gelten lassen. Er citirt wörtlich einen

1) E. Salkowski, Berliner klinische Wochenschrift. Festnummer für C. A. Ewald. 1905.

2) Siehe Kausch, Trauma und Diabetes mellitus und Glykosurie. Zeitschrift f. klinische Medic. Bd. 55. 1904. - Ferner Rose, Arch. f. exper. Pathol. u. Pharmakol. Bd. 50.

3) Siehe z. B. Rédard, Sur la glycosurie éphémère dans les affections chirurgicales. Revte de chirurg. 1886 p. 715. 
längeren Satz von mir, der mit den Worten schliesst: „Die langdauernde Narkose, die unvermeidliche Verletzung von zahlreichen Nervenästen $\mathrm{mag}$ das verhältnissmässig häufige Vorkommen dieser Glykosurien nach der Operation an den Speicheldrüsen erklären". Nun: "mag erk]ären", damit dürfte doch nicht nur das Hypothetische der Annahme, sondern auch die Concession an ihre Vertreter zur Genüge angedeutet sein. Es ist vielleicht auch heute noch nicht sicher zu entscheiden, ob eine solche Erklärung richtig oder falsch wäre. Aber darauf kam es ja zunächst gar nicht an! Das, was ich sagen wollte, war doch nur - wie aus dem Zusammenhange ohne Weiteres ersichtlich - dass man für diese Glykosurien allenfalls die Erklärung gelten lassen könnte, nicht aber für den Pankreasdiabetes. Ich habe die ausserordentlich mühevollen Versuche an den Speicheldrüsen nur ausgeführt, um zu sehen, ob in der That, wie de Renzi und Reale ${ }^{1}$ ) es behauptet hatten, die Exstirpation der Speicheldrüsen die gleichen Folgen hätte wie die Pankreasexstirpation. Ich kam zu dem Schlusse, dass die geringfügige, vorübergehende, nicht regelmässig auftretende Zuckerausscheidung, die ich einige Male nach Operationen an den Speicheldrüsen beobachtet hatte, unmöglich mit dem schweren, andauernden und ausnahmslos auftretenden Pankreasdiabetes auf eine Stufe gestellt werden kann. Ich suchte es dann durch die Analyse der Versuche im Einzelnen, sowie durch Combination der Speicheldrüsen- mit der Pankreasexstirpation noch näher zu begründen, dass ndie Speicheldrüsen an der Function des Pankreas bei dem Verbrauche des Zuckers im Organismus nicht theilnehmen". Die von mir beigebrachten Beobachtungen sind vorläufig noch von Niemand widerlegt, und ich darf daher meine Beobachtungen einstweilen in vollem Umfange aufrecht erhalten.

In Bezug auf die von Falkenberg ${ }^{2}$ ) nach der Exstirpation der Schilddrüse, übrigens auch nicht regelmässig, beobachtete Glykosurie hatte ich bemerkt, dass es "schwer zu entscheiden" sei, wie diese Glykosurie zu Stande kommt. Ich selbst batte damals nur bei einem einzigen Hunde die Schilddrüse exstirpirt, ohne eine Zuckerausscheidung beobachtet zu haben. In zahlreichen späteren

1) Verhandl. d. X. intern. medic. Congr. zu Berlin 1890 Bd. 2 Abth. 5 S. 97.

2) Verhandl. d. X. Congresses f. innere Medic. Wiesbaden 1891 S. 502. 
Versuchen mit Schilddrüsenexstirpation habe ich, beiläufig . bemerkt, ebensowenig jemals Glykosurie auftreten sehen. Ich darf daher hier ebenfalls meine Behauptung aufrecht erhalten, dass auch der Schilddrüse nicht in gleicher Weise wie dem Pankreas eine besondere Function bei dem Verbrauche des Zuckers im Organismus zukommt, und dass somit die Function des Pankreas eine specifische und diesem Organe allein eigenthümliche ist.

Ich kann übrigens nicht finden, dass, selbst wenn meine Annahmen in Bezug auf die Function der Speicheldrüsen oder der Schilddrüse nicht zutreffend gewesen wären, dieses den Werth meiner Versuche über den Pankreasdiabetes irgendwie beeinträchtigt hätte. Ich weiss daher nicht, warum es $\mathrm{P}$ fl üger so ganz besonders verdächtig ersehien, dass ich in meiner "Abwehr" diese immerhin nebensächlichen Fragen nicht noch ein Mal erörtert habe.

Wichtiger ist es schon, dass Pflüger auch jetat noch bei der Bebauptung bleibt, meine Totalexstirpationen des Pankreas wären "mangelbaft ausgeführt und nur als Partialexstirpationen zu betrachten". Diese Behauptung war es, die ich "als eine nicht auf Kenntniss von Thatsacben beruhende, sondern nur auf Trugschlüssen aufgebaute Vermuthung" nachdrücklich zurückweisen zu müssen glaubte. Pflüger wiederholt nun demgegenüber dass er sein Urtheil „auf ein breites Material von Thatsachen begründet und strenge bewiesen habe".

Hier scheinen unsere Auffassungen darüber, was "Thatsache" und was "Schlussfolgerung“ ist, etwas zu divergiren. Ich muss mich also klarer ausdrücken:

Als Thatsachen sehe ich es an, dass Pflüger bei 13 Totalexstirpationen des Pankreas, die Herr Prof. O. Witzel ausgeführt hat, in keinem Falle "Abnormitäten des Hungers und Durstes bemerkt" hat, dass "niemals seine Hunde den Koth gefressen" haben. Ich zweifle nicht, dass die Pankreasexstirpation in diesen Fällen im strengsten Sinne des Wortes eine vollständige war, auch nicht, dass einzelne der operirten Thiere bis zu 16 und 19 Tagen gelebt haben, dass die Bauchwunde bei keinem dieser Thiere heilte und „immer bis zum Tode eiterte", dass "stets kleine Abscesse in der Bauchhöhle" gefunden wurden.

Ebenso muss ich es aber als Thatsachen hinstellen, dass auch 
ich bei meinen Totalexstirpationen des Pankreas, die ich in sehr viel grösserer Zahl nach dem gleichen Verfahren schon früher ausgeführt habe, das Organ ebenso vollständig exstirpirte, dass ich sehr viele Thiere gesehen habe, die sich ebenso verhielten wie die von Pflüger beobachteten, dass ich aber auch solche Thiere gesehen habe, bei denen absolut nichts mehr vom Pankreas zurïckgeblieben war, die aber doch keine Eiterungen mehr aufzuweisen hatten, und die auch eine abnorme Gefrässigkeit und ein abnorm gesteigertes Durstgefühl an den Tag legten, sowie abnorm grosse Harnmengen entleerten.

Das sind Thatsachen! Ich zweifle nicht an der Wahrheit der von Pflüger gemachten Angaben, dulde aber auch keinen Zweifel an meiner eigenen Glaubwürdigkeit!

Wenn Pflüger aber nun diese beiden Reihen von Thatsachen für unvereinbar hält, wenn er aus der Richtigkeit seiner Beobachtungen die Unrichtigkeit nı einer Angahen folgern zu müssen glaubt, wenn er namentlich in dem Auftreten von Polyphagie und Polydipsie einen Beweis für die Unvollständigkeit meiner Exstirpationen erblickt, so nenne ich dieses: unzutreffende Schluss. folgerungen, und hoffe dieses hier ausreichend begründen $\mathrm{zu}$ können:

Ich hatte geglaubt, es müsste gentigen, wenn ich Herrn Geheimrath Pflüger darauf aufmerksam machte, dass meine Operationsmethode mit der von Witzel beschriebenen identisch ist, um ihn zu überzengen, dass auch meine Operationen zweifellose Totalexstirpationen waren., Hierin habe ich mich geirrt. Pflüger behauptet nach wie vor, dass "Witzel's Methode der von O. Minkowski vorzuziehen ist", und dass "durch die Thatsache die Behauptung von 0 . Minkowski widerlegt ist, dass Witzel's und seine Methode identisch seien". Er habe gleich von Anfang an gewünscht, dass bei ihm die Exstirpation "nicht nach O. Minkowski's Muster" ausgeführt werde. Worin allerdings die wesentlichen Unterschiede beider Operationsmethoden bestehen, das sagt Pflüger nicht. Es dürfte auch nicht ganz leicht sein, das zu sagen - man braucht nur die von Witzel im Jahre 1905 gegebene Beschreibung mit der von mir im Jahre 1893 veröffentlichten zu vergleichen ${ }^{1}$ ).

1) Hier muss ich leider auf die von Pflüger (l. c. S. 9) gebrachte Erklärung des Herrn Professor Witzel eingehen: Ich habe Herrn Professor 
Ganz sicher scheint auch Pflüger in diesem Punkte nicht mehr zu sein, denn er weist an anderer Stelle darauf hin, dass "zwei Operateure, die das Pankreas nach derselben Methode exstirpiren, doch zu sehr verschiedenen Ergebnissen gelangen können. -Dem einen gelingt die absolute Entfernung der Drüse, dem anderen nicht. Denn es gehört, besonders am Dünndarm, ein sehr scharfes Auge dazu, un die dünnen Drüsenläppchen immer sicher von Fettläppchen zu unterseheiden." Ich weiss aber nicht, was Pflüger berechtigt, mir diese Schärfe des Auges abzusprechen. In meiner Arbeit habe ich jedenfalls zur Genüge betont, wie wichtig es sei, „die kleinen Fortsätze und Läppchen der Drüse, welche mitunter nach den verschiedensten Richtungen hin sich weitab erstrecken, zu erkennen und sie von Lymphdrüsen und Fettgewebe zu unterscheiden". Ich erwähnte auch, dass ich „der sorgfältigen Beachtung dieses Umstandes es zu verdanken hatte, dass ich bis jetzt noch $\mathrm{k} \in \mathrm{in}$ einziges Mal irgend ein noch so kleines Stück des Pankreas wider Willen in der Bauchhöhle zurückgelassen habe".

Dass ich bei meinen Totalexstirpationen des Pankreas das Organ wirklich vollständig zu entfernen pflege, dafür könnte auch ich, wie Pflüger, das Zeugniss von Chirurgen beibringen, die meinen Operationen beigewohnt, und von Anatomen, die die Sectionen meiner

Witzel keineswegs den Vorwurf eines Plagiats gemacht. Denn ich hatte mich mit seiner mir persönlich abgegebenen Erklärung begnügt, er habe "die Operation auf Pflüg er's Wunsch nur einfach so beschrieben, wie er sie auミgeführt hätte, die Berücksichtigung der Litteratur habe er Pflüger selbst überlassen". Ich habe auch nur, wie gesagt, die Identität unserer Operationsmethoden hervorhoben, um die Einwände gegen die Zuverlässigkeit meiner eigenen Operation zu entkräften. Jetzt erklärt Herr Prof. Witzel, er habe nur aus "collegial geübter Höflichkeit" gegen meine Auffassung nichts "einzuwenden haben wollen". Wenn dem so ist, so verzichte ich gerne auf solche "collegiale Höf lichkeit" zu Gunsten der Wahrbeit! Herr Prof. Witzel mag nun wollen! Ich fordere ihn auf, nunmehr anzugeben, in welchem wesentlichen Punkte er meine Operationsmethode abgeändert oder verbessert hat. Dass meine Beschreibung nur „fragmentarisch“ war, möchte ich bezweifeln. Für einen einigermaassen geübten Chirurgen musste das, was ich auf sechs Druckseiten "zur Technik der Operation" angegeben hatte, vollkommen ausreichead sein; um wieviel mehr für einen „grossen Meister der Chirurgie", wie Herr Prof. Witzel es unbestritten ist! In einer soeben er' schienenen Arbeit von $Z \mathbf{u n z}$ et Mayer (Bulletin de l'académie royale de médecine de Belgique séance, de 30. Sept. 1905) bemerken die Autoren ausdrücklich: Minkowski a développé de façon très précise la technique à laquelle il a eu recours. 
Thiere gesehen haben. Aber ich verzichte auf Eilleshelfer! Ich denke wie James Moore, der im Jahre 1807 den Ausspruch tbat ${ }^{x}$ ): "Time alone establishes truth in medicine. A real discovery needs not the aid of oaths, nor the zealous testimony of the grateful."

Die Zeit hat schon jetzt zu meinen Guısten entschieden. Denn sie hat die Bestätigungen meiner Resul ta te gebracht, Bestätigungen durch zuverlässige Autoren - durch Ed uard Pflüg er selbst!

Vergleichen wir einmal unsere Operationsergebnisse: Pflüger hat 13 Totalexstirpationen ausgeführt, und dabei niemals eine Heilung: der Bauchwunde beobachtet. Ich hatte angegeben, dass "von 63 operirten Thieren nur 17 länger als 8 Tage gelebt haben". Allerdings wurde ein Theil dieser Thiere frübzeitig getödtet, um den Glykogengehalt ihrer Organe zu bestimmen, dafür aber hatten auch noch von jenen 17 weitaus die meisten an Eiterungen gelitten und gingen auch später noch zum Theil an den Folgen des operativen Eingriffs zu Grunde. Icb selbst betonte, dass nach der vollständigen Exstirpation „nur wenige der operirten Thiere den Eingriff gut genug überstehen, um für längere Beobachtungsreihen verwerthet werden zu können," dass es, sobald der Diabetes in voller In tensität auftrat, nur "in seltenen Fällen noch möglich war, eine Heilung per primam intentionem zu erzielen", dass "weitaus der grösste Theil der operirten Thiere direct oder indirect an den Folgen des operativen Eingriffs zu Grunde ging".

Ich wies darauf hin, dass es keineswegs etwa die mangelhafte Anwendung der Asepsis war, die meine ungünstigen Resultate verschuldete. Denn durch die von mir beobachteten Cautelen gelang es, „bei allen Operationen, nach welchen die Thiere nicht diabetisch wurden, fast ausnahmslos glatte Heilung zu erzielen, obgleich die Verletzungen hierbei häufig noch complicirter waren als nach der totalen Exstirpation des Pankreas."

Sind denn nun unsere Resultate wirklich so verschieden? Wenn Jemand vielleicht doch noch im Stillen gedacht haben sollte, meine schlechten Operationsergebnisse nach der Totalexstirpation könnten durch irgend welche Mängel meiner operativen Technik bedingt sein, - dass selbst ein Witzel nicht bessere Resultate erzielen konnte, durfte gewiss zu meiner Rechtfertigung dienen!

1) Siehe Medico-chirurgical Transactions vol. 1. London 1815. Bericht über die Sitzung rom 18. März 1807. 
Gerade diese Schwierigkeiten, nach der Totalexstirpation eine Heilung der Bauchwunde zu erzielen und die Thiere bei gutem Allgemeinbefinden zu erhalten, waren es, die mich veranlassten, an Stelle der einfachen Entfernung der Drüse in einer Sitzung, die dreizeitige Operation auszuführen, uber welche ich in meiner Arbeit ausführlich berichtet babe. Auch bei diesen Versuchen handelte es sich um Totalexstirpationen, und ich kann dieses Verfahren, dessen ich mich jetzt fast ausschliesslich bediene, nur auf das Wärmste empfehlen, wenn es darauf ankommt, diabetische Thiere zu erhalten, an welchen die zu beobachtenden Stoffwechselvorgänge nicht durch complicirende Eiterungs- und Entzündungsprocesse beeinflusst werden sollen.

Das Verfahren bei dieser dreizeitigen Operation ist ein etwas Umständliches, und das hat offenbar bis jetzt die meisten Bearbeiter des Pankreasdiabetes davon abgeschreckt, diese Operationsmethode zu versuchen. Ich habe die Technik dieses Verfahrens in meiner Arbeit aus dem Jahre 1893 ausführlich beschrieben: Es wird bei der ersten Operation das aborale Ende des Pankreas, welches bei Hunden in der Regel einen für diesen Zweck sehr bequemen Gefässstiel hat, unter die Bauchhaut verlagert. Es empfieblt sich - wie ich hier ergänzend hervorheben möchte - zu diesen Zwecke den Hautschnitt am lateralen Rande des rechten M. rectus abdominis, parallel diesem Rande, anzulegen. Die M. M. obliqui und transversus werden am besten stumpf in der Richtung ihres Faserverlaufs durchtrennt, das Peritoneum in nicht zu grosser Ausdehnung eröffnet. Bei einiger Uebung gelingt es dann mit einem Griffe den absteigenden Theil des Duodenums in die Wunde zu ziehen und die Stelle aufzusuchen, wo das aborale Ende des Pankreas sich vom Darme entfernt. Man überzeugt sich zunächst, ob die Gefässversorgung des untersten Pankreasendes die normale ist. Ausnahmsweise, im Ganzen aber selten, kommt nämlich eine Anordnung der Gefässe vor, bei der die Bildung eines frei beweglichen Gefässstieles Schwierigkeiten macht; dann ist das Thier für den Versuch nicht gut zu gebrauchen. Ist das Letztere nicht der Fall, dann bindet man das aborale Stäck an der Stelle, wo es den Darm verlässt, vom übrigen Pankreas mittelst doppelter Ligaturen ab und durchtrennt zwischen beiden Ligaturen. Dabei achtet man darauf, dass kein zerquetschtes Pankreasgewebe in der Bauchhöhle zurückbleibt. Man durchschneidet nun das Mesenterium so weit, dass das aborale Stück des Pankreas bequem aus der Bauchhöhle herausgeführt werden kann, ohne dass der lange Gefässstiel dabei eine Zerrung erfährt. Man bringt das Duodenum mit dem Pankreasrest in seine normale Lage zarück, schliesst die Peritoneal-, Muskel- und Fascienwunde durch ein paar Seidennähte, die man so anlegt, dass das herausgezogene Pankreasstück nicht mehr in die Bauchhöhle zurückschlüpfen kann, ohne dass edoch die Blutcirculation im Gefässstiel gehemmt wird, und lagert nun dieses Pankreasstück in eine Hauttasche. Diese legt man am besten nach rechts von der Wunde an, und zwar möglicbst oberflächlich, jedenfalls ausserhalb der Fascie, 
damit die letzte Operation, die Entfernung des verlagerten Pankreasstückes, sich später so wenig eingreifend als möglich gestalte. Das abgeschnittene Ende des verlagerten Pankreasstückes führt man am besten durch einen kleinen Schlitz, den man am oralwärts gelegenen Ende der Hanttasche anlegt, durch die Haut nach aussen, und fixirt es hier durch einige Nähte, wenn irgend möglich so, dass der Ausführungsgang gleich offen bleibt. So kann sich hier eine Fistel bilden, aus der der Pankreassaft nach aussen abfiiesst. Man achtet darauf, dass der Gefässstiel nicht torquirt wird, und schliesst die Hautwunde recht sorgfältig durch oberflächliche Nähte.

Das verlagerte Pankreasstïck schwillt meist in den ersten Tagen etwas an; oft entsteht auch vorübergehend etwas Oedem in der Umgebung, aber in der Regel gelingt es sehr leicht, das Stïck zur Einheilung zu bringen. Man kann das gute Erhaltensein der Function dieses Drüsenstückes daraus erkennen, dass aus der angelegten Fistel sich ein wasserklarer Pankreassaft entleert, der äusserst wirksame Fermente enthält. Sorgt man dafür, dass die Fistel offen bleibt, dann tritt auch nach längerer Zeit keine nennenswerthe Verhärtang und Degeneration des verlagerten Drüsenstücks ein.

Erst wenn dieses Drüsenstück gut eingeheilt, die Hautnähte entfernt und die Wunde vollständig vernarbt ist, schreitet man zur zweiten Operation. Man lert jetzt den Schnitt in der Linea alba an, eröffnet das Peritoneum seitlich von dem präperitonealen Fettwulst und entfernt den in der Bauchhöhle zurückgebliebenen Theil des Pankreas in gleicher Weise wie bei der Totalexstirpation. Die Wundheilung nach der ersten Operation ist in meinen Versuchen fast immer eine so glatte gewesen, dass das Peritoneum bei der zweiten Operation vollkommen normal gefunden wurde und auch an der Stelle, wo das Pankreas durchschnitten war, stärkere Verwachsungen nicht angetroffen wurden.

Nach der zweiten Operation stellt sich oft, aber nicht immer, eine mitunter zicmlich intensive, aber meist nach wenigen Stunden schon vorübergehende Glykosurie ein ${ }^{1}$ ). Ist das verlagerte Stück aber gross genug, ist es genügend ernährt, und ist der Secretabfluss ungehindert - was sich alles leicht erreichen

1) Diese vorübergehende Glykosurie ist möglicher Weise nur auf die unvermeidliche Zerrang der das verlagerte Pankreasstück versorgenden Gefässe bei der zweiten Operation zu beziehen. Vielleicht aber spielt hier noch ein besonderes Moment mit: Es schien mir in einigen Fällen, als ob, nach der Entfernung des intraabdominalen Paukreasrestes, aus dem extrabdominal gelegenen Stück ein lebhafterer Secretabfluss sich bernerkbar machte. Es war, als ob das nach dieser Operation nur noch allein erhaltene Drüsenstück nunmehr in grösserem Umfange für die Functionen der entfernten Organtheile vicariirend einzutreten beginnt. Es wäre nun denkbar, dass auch die Leistungen des verlagerten Pankreasstïckes beim Zuckerumsatz erst mit dem Fortfall aller übrigen Drüsentheile in stärkerem Maasse in Anspruch genommen werden, dass das kleine Drüsenstück diesen Ansprüchen im ersten Augenblicke nicht voll genügen kann, sich aber bald an die erhöhten Forderungen anpasst. Es wäre vielleicht von Interesse, die Frage nach dieser Richtung weiter zu verfolgen. 
lässt - so wird das Thier nicht diahetisch und verträgt selbst die grössten Kohlehydratmengen, ohne Zucker im Harn auszuscheiden.

Auch nach dieser zweiten Operation macht die Wundhcilung meist keine besonderen Schwierigkeiten. Man wartet nun bis die Bauchwunde vollständig vernarbt ist, bis nirgends mehr Hautabscesse oder Eiterungen an den Stichkanälen zu bemerken sind, und bis der Hund sich vollständig von den Operationen erbolt hat. Solche Thiere können bei geeigneter Pflege nicht nur ihren Körperbestand erhalten, sondern sogar noch beträchtlich an Körpergewicht zunehmen.

Die dritte Operation gestaltet sich num ausserordentlich einfach: Man umschneidet die Fistel und führt den Hautschnitt so weit, als das verlagerte Pankreasstück reicht, schält nun das Drüsenstück stumpf ans dem umgebenden subcutanen Bindegewebe heraus, legt eine Ligatur um den Gefässstiel und entfernt das Drüsenstück in Toto. Dann schliesst man die Hautwunde, die bisweilen per primam beilt, 'aber auch dann, wenn dieses nicht der Fall ist, das Allgemeinbefinden der Thiere nicht beeinträchtigt, sofeln man nur dafür sorgt, dass eine Eiterretention nicht stattfindet. Nach dieser Operation tritt ausnahmslos der Diabetes auf.

So kann man durch eine wenige Minuten dauernde gefahrlose Operation, bei welcher die Bauchhöhlegar nicht mehr eröffnet wird, und bei der nur eine einzige Ligatur und einige wenige oberflächliche Hautnähte anzulegen sind, einen Diabetes von höchster Intensität erzeugen, der bis zum Tode der Thiere andauert.

Es ist klar, welch entscheidende Bedeutung den Beobachtungen an solchen Thieren für die Beurtheilung der Pankreasfunction beigelegt werden musste. Diese Versuche scheint aber Pflüger nicht zu den Totalexstirpationen zu zählen, vermuthlich, weil er auch gegen sie noch etwas Besonderes einzuwenden hat.

Einstweilen aber darf darauf hingewiesen werden, wie gerade diese Versuche geeignet sind, die Unrichtigkeit der Vorstellungen darzuthun, die sich PfIüger über die Wirkungen des operativen Eingriffs gebildet hat. Sie zeigen zunächst, dass es keineswegs richtig 'sein kann, dass die Glykosurie besonders dann beobachtet wird, wenn der operative Eingriff mit geringerer Schonung ausgeführt wird. Das Umgekehrte ist richtig: Die Glykosurie tritt mit u na so grösserer Intensität in die Erscheinung, je schonender das operationsverfahren ist, und je weniger das Allgemeinbefinden der Thierebeeinträchtigt ist.

Auch nach dieser dreizeitigen Operation gehen die Thiere in wenigen Wochen zu Grunde, selbst dann, wenn die kleine Haut- 
wunde sich innerhalb der ersten 24 Stunden per primam geschlossen hat. Sie gehen nicht an Eiterungen zu Grunde, aber an ihrem Diabetes, sie sterben, weil der vollständige Ausfall der Pankreasfunction die Erhaltung des Lebens unmöglich $\operatorname{macht}^{1}$ ).

Von irgendeiner "Reizwirkung der Operation in der Bauchhöhle" als Ursache des Diabetes kann bei diesen Thieren nicht die Rede sein. Solange das transplantirte Pankreasstück ausreichend functionirt, verläuft der Zuckerstoffwechsel vollkommen ungestört, trotzdem die Bauchbölle zwei Mal eröffnet wurde, trotzdem die Verletzungen der Abdominalorgane, die Zahl der in der Bauchhöhle zurückbleibenden Ligaturen - bis auf eine einzige - die gleiche ist wie bei der Totalexstirpation, somit also auch, ebenso wie nach dieser „zahlreiche Knoten der Unterbindungsfäden als fremde Körper in der Bauchhöhle zurückbleiben und dauernde Reizungen der pankreatischen Nervenstümpfe unterhalten" ${ }^{2}$ ) könnten. Nach den ersten beiden Operationen heilt die Laparotomiewunde ganz glatt. Es bleiben keine Abscesse in der Bauchhöhle zurück. Die ganze Gegend am Duodenum kann später bei der Section so aussehen, als ob dort niemals ein Pankreas gewesen wäre. Soll nun der geringfïgige Eingriff der Entfernung des subcutan gelegenen Pankreasstückes, die Unterbindung des einzigen Gefässstranges, welches dieses Drüsenstück noch versorgt, den mächtigen "Nervenreiz" abgeben, der den Diabetes höchsten Grades auslöst? Dieser Eingriff, der, solange noch anderswo ein Pankreastheil vorbanden ist, für das Thier ganz gleichgültig ist!

Es ist zweifellos nur der vollständige Ausfall sämmt-

1) Ich möchte übrigens bei dieser Gelegenheit bemerken, dass auch die schlechte Wundheilung nach der Totalexstirpation nicht sowohl, oder wenigstens nicht allein, auf die Ueberladung des Organismus mit Zucker, als vielmehr auf das vollständige Fehlen der Pankreasfunction zu beziehen ist. Lässt man bei partieller Exstirpation nur ein so kleines Stäck von der Drüse zurück, dass dieses nicht ausreicht, um das Zustandekommen des Diabetes zu verhindern, dann kann, auch trotz langdauernder Eiterung, schliesslich doch noch eine vollkommene Vernarbung der Wunden zu Stande kommen, selbst wenn man, wie ich dieses gethan habe, bei einem solchen Thiere durch Kohlehydratzufuhr in der Nahrung eine dauernde Glykosurie von $6-8 \%$ unterhält.

2) Siehe Pflüger, 1. c. S. 10. 
licher Pankreasfunctionen, mit dem nicht nur die Fähigkeit erlischt, den Zucker im Organismus in normaler Weise zu verwerthen, sondern auch die Ausnutzung der Nahrung und vielleicht auch manche andere Functionen in einer Weise geschädigt werden, die mit der Erhaltung des Lebens nicht vereinbar ist. Die Thiere gehen daher zu Grunde, trotzdem sie reichlich ernährt werden können. Weil ihre Verdauungsorgane durch den letzten entscheidenden operativen Eingriff direkt nicht lädirt werden, ist die Nahrungszufuhr nicht gestört. Weil die Thiere ihre Nahrung nicht genügend verwerthen, ist ihr Nahrungsbedürfniss sogar ein gesteigertes. Die dreizeitig operirten Thiere zeigen daher fast immer jene Polyphagie, Polydipsie und Polyurie, die aus leicht begreiflichen Gründen nach der einzeitigen Totalexstirpation dann ausbleiben können, wenn die Thiere an den Folgen des operativen Eingriffs kranken.

Diese vom Menschen her so bekannten Begleiterscheinungen des Diabetes hat nun Pflüger bei seinen 13 Totalexstirpationen stets vermisst, ebenso wie einige andere Autoren, die das Pankreas vollständig "in einer Sitzung entfernten. Ich hätte, nach meinen Erfahrungen, darin njchts Auffälliges erblickt. Aber für Pflüger ist dieses die wichtigste "Thatsache", welche die Unvollständigkeit der Exstirpation „beweist". Und das muss ich leider immer noch als einen "Trugschluss" bezeichnen!

Man könnte es auf den ersten Blick überhaupt schwer verständlich finden, dass Pflüger diese Differeuz in unseren Beobachtungen für so wesentlich hält. Wie leicht hätte man das verschiedene Verhalten unserer Thiere durch irgendwelche Nebenumstände, z. B. die verschiedene Fütterungsart, erklären können! P flüger verfütterte meist ausgekochtes Kabeljaufleisch und Nutrose, ich gab meinen Thieren oft frisches Fleisch, Mileh, Butter und Brod. Aber Pflüger legt der Polyphagie und Polydipsie eine ganz besondere Bedeutung bei, und das erklärt sich aus einer eigenthümlichen Theorie, die er in Bezug auf diese Erscheinungen aufgestellt hat. Er meint: „Der unstillbare Durst und Hunger beweisen eine auf das Heftigste gesteigerte Erregung der Hunger- und Durstnerven, welche durch die Verwundung der Bauchhöhle junzweifelhaft bedingt ist."

Es ist mir nicht recht klar geworden, warum diese Erregung der Hunger- und Durstnerven nach der vollständigen Pankreas- 
exstirpation sich nicht bemerkbar macht. Aber ich zweifle nicht, dass man auch hierfür eine Erklärung finden könnte. Auffallend finde ich es nur, dass von dieser „auf das Heftigste gesteigerten Erregung der Hunger- und Durstnerven, welche durch die Verwundung der Bauchhöhle unzweifelhaft bedingt ist", bis jetzt noch kein Chirurg bei irgendeiner der vielen Tausende am Menschen ausgeführten Laparotomien etwas gemerkt hat. Sollte der Mensch in seiner Bauchhöble keine Hunger- und Durstnerven haben? Oder sollte nicht am Ende das Ausbleiben der Polyphagie nach der Totalexstirpation des Pankreas eine sehr viel einfachere Erklärung haben?

Es ist doch eine jedem Arzt bekannte Thatsache, dass auch ein Diabetischer seinen Appetit verliert, wenn er "krank" ist. Ein französischer Autor drückte das mit den Worten aus: „pour être diabétique il faut être bien portant." $\mathrm{Krank}$ waren aber doch die Hunde sicher, deren "Bauchwunden niemals heilten" und die "stets Abscesse in der Bauchhöhle" hatten!

Das wollte ich auch nur sagen, als ich schrieb: "Ich glaube ganz gerne, dass Pflüger und einige andere Autoren, die nur solche Hunde gesehen haben, die nach der Totalexstirpation des Pankreas ausnabmslos in kurzer Zeit an Eiterungen zu Grunde gingen, bei diesen Thieren Polyphagie und Polydipsie vermisst haben." Die in meinem Manuscripte enthaltenen Worte "an Eiterungen" sind nun durch eine unglückliche Laune des Zufalls vom Setzer ausgelassen worden, und ich habe diesen Druckfehler leider bei der Correctur übersehen. Aber deshalb branchte mir Pflüger nicht gleich eine "absolut unwahre Behauptung" vorzuwerfen ${ }^{\mathbf{1}}$ ). Denn aus dem nächsten Satze geht es deutlich hervor, was ich gemeint hatte, indem ich fortfubr: "Auch ich habe selbstverständlich in vielen Fällen, in welchen die Thiere an peritonitischen Entzündungen und Eiterungen krankten, die Gefrässigkeit vermisst . . . Aber ... ich habe a u ch solche Thiere gesehen, die selbst nach der Totalexstirpation noch eine auffallende Polyphagie und Polydipsie an den Tag legten." In den Worten "nur" und

1) Diesen Vorwurf begründet Pflüger damit, dass er ausdrücklich hervorgehoben hätte, dass von seinen Hunden einer 16, ein anderer 19 Tage die Totalexstirpation überlebt habe. Von diesen Hunden hatte aber der erstere bei der Section "mehrfache Perforationen des Duodenums und Geschwüre der Schleim. haut in nächster Nachbarschaft der Durchbohrungen", der zweite einen "eitrigen Abscess". 
"auch" sollte die Erklärung für die Differenz in unseren Beobachtungen liegen. Keineswegs aber lag in meiner Bemerkung irgendein Tadel für die von Pflüger und anderen Autoren ausgeführten Versuche. Ich betonte ja ausdrücklich, dass auch ich selbst in vielen Fällen die gleichen Beobachtungen gemacht hatte.

Damit erledigt sich zugleich das, was Pflüger aus den Beobachtungen von Paul Schulz und Georg Zülzer, sowie aus dem von ihm angeführten Versuche von Sandmeyer gegen mich folgern will. Diese Beobachtungen stehen durchaus nicht im Widerspruch mit meinen Erfahrungen. Nur habe ich a usser den gleichen a uch noch andere Beobachtungen gemacht!

Dass $\mathrm{L} u ̈ \mathrm{thje}$ bei vermeintlich totalen Exstirpationen des Pankreas, indem er die schwieriger entfernbaren Parthien der Drüse mit dem Paquelin abbrannte, kleine Drüsenreste zurückgelassen hat, ist gewiss etwas, was unmöglich gegen mich ins Feld geführt werden kann; denn niemals habe ich das Abbrennen mit dem Paquelin bei der Pankreasexstirpation angewandt oder empfohlen. Im Gegentheil, ich habe ausdrücklich die doppelte Unter. bindung und Durchschneidung auch der kleinsten Gefässe als unerlässlich bezeichnet. Diese meine Vorschrift ist allerdings leider nicht von allen Autoren befolgt worden, die nach mir das Pankreas exstirpirt haben. Aber Witzel hat sie befolgt.

Um die Unzuverlässigkeit meiner Operationen darzuthun, führt Pflüger anch noch einmal meine Versuche an Vögeln und Fröschen an. Ich hätte geglaubt, auf diese Versuche, weil sie von untergeordneter Bedeutung waren, nicht näher eingehen za dürfen. Da aber P flüg er wi d erholt darauf zurückkommt, so seien mir auch hierüber einige Worte gestattet:

Ich hatte in meiner Arbeit hervorgehoben, dass keineswegs alle Thierarten sich in gleicher Weise gegenüber der Pankreasexstirpation verhielten. Dabei teilte ich mit, dass „bei Vögeln (Tauben und Enten) nach der Pankreasexstirpation eine $\mathrm{Zuckerausscheidung} \mathrm{nicht} \mathrm{zu} \mathrm{Stande} \mathrm{komme“.} \mathrm{Dass} \mathrm{es} \mathrm{bei} \mathrm{den}$ Vögeln, obwohl das Pankreas bei ihnen sehr viel leichter zugängig ist als bei Säugethieren, "nicht leicht ist, das Organ vollständig zu entfernen, ohne eine zur Nekrose führende Ernährungsstörung des Darmes zu bewirken ", hatte ich ausdrücklich erwähnt. Doch erwiesen sich die Schwierigkeiten für mich als nicht unüberwindlich. Kausch, der damals noch nicht der geübte Chirurg war, der er jetzt ist, empfand diese Schwierigkeiten in stärkerem Maasse. Er hielt es für „unmöglich, das Pankreas total zu entfernen, ohne die Duodenalgefässe mitzunehmen". Insbesondere vermochte er nicht ohne Verletzung dieser Gefässe einen „spitz zulaufenden, schmalen Zipfel der Drüse zu entfernen, der sich ziemlich scharf auf das scheinbare Pankreasende aufsetzt und noch etwa

E. Pflüger, Archiv für Physiologie. Bd̃. 111 . 
$1 \mathrm{~cm}$ weiter oralwärts, dicht ventral den Gefässen anliegend, ungefähr bis zu der Stelle verläuft, wo sich die Vena pencreatico-duodenalis mit anderen grossen Darmvenen zur Pfortader vereinigt." Mir war auch dieser Zipfel der Drüse keineswegs verborgen geblieben. Es gelang mir aber, auch diesen zu entfernen, und ich konnte daher in meiner Arbeit ausdrücklich erwähnen, dass „bei der Section kein e Spur von Pankreasgewebe mehr gefunden wurde". Ka usch zog es vor, um die Darmnekrose zu verhüten, das bequemere Verfahren zu wählen, welches ich zunächst vermieden hatte, um eine reinere Versuchsanordnung zu haben. Er resecirte das ganze Duodenum mit den Duodenalgefässen, wie es übrigens schon Weintraud in einem von mir mitgetheilten Versuche ausgeführt hatte. Auch nach dieser Operation trat eine Zuckerausscheidung im Harne in der Regel nicht auf.

Bei der weiteren Verfolgung des Gegenstandes fand nun Kausch1), dass auch bei den Vögeln dem Pankreas eine gewisse Bedeutung für den Zuckerstoffwechsel zukommt: nach der Exstirpation der Drüse trat in der Regel zwar keine Glykosurie, wohl aber eine Hyperglykämie anf. In einer späteren Arbeit ermittelte dann $\mathrm{Kausch}^{2}$ ) noch, dass der Zuckerverbra uch im Organismus des Vogels nach der Pankreasexstirpation nicht aufgehoben ist, sondern höchstens „etwas, wenn auch nur wenig“ langsamer verläuft als beim Thier mit Pankreas.

Man könnte vielleicht darüber streiten, ob Kausch berechtigt war, die von ihm gefundene Hyperglykämie, die in der Regel ohne Glykosurie und ohne wesentliche Störung des Zuckerverbraucbs einherging, als "Diabetes" zu bezeichnen. In dem Worte liegt doch eigentlich der Uebergang von Zucker in den Harn. Jedenfalls aber ist die Thatsache, dass die Vögel sich nach der Pankreasexstirpation anders verhalten als die Hunde und in der Regel eine Zackerausscheidung in Harne nach dieser Operation nicht zeigen, auch durch Kausch bestätigt, und ich habe daher die Untersuchungen ron Kausch nicht als eine Widerlegung, sondern stets nur als eine Ergänzung meiner eigenen Untersuchungen angesehen. -

Auf die Beobachtungen an Fröschen näher einzugehen, kann ich wohl verzichten, da Pflüger selbst hier jetzt ein „vielleicht" einschiebt. Ich hatte ja auch nur bemerkt, dass es bei Fröschen "mir nicht gelungen ist", durch Exstirpation der Bauchspeicheldrüsen einen Diabetes hervorzurufen. Die Schwierigkeiten, bei den engen räumlichen Verhältnissen das Pankreas ohne wesentliche Nebenverletzungen vollständig zu entfernen, stehen bier in solchem Missverhältnisse zu der Bedeutung der zu erwartenden Resultate, dass man wirklich den Frosch als ein für die Erforschung des Pankreasdiabetes nicht sehr geeignetes Thier bezeichnen darf. Wer meine Angaben über diese Versuche an Fröschen mit den Resultaten der anderen Autoren genauer vergleicht, wird wohl zugeben, dass hier unlösbare Widersprüche nicht bestehen.

1) Kausch, Arch. f. exper. Pathol. u. Pharmakol. Bd. 37. 1896.

2) Ibid. Bd. 39. 1897. 
So glaube ich denn gezeigt zu haben, dass alle Widersprüche, die Pflüger zwischen meinen Angaben und den von ihm selbst oder von anderen Autoren gemachten Beobachtungen zu finden glaubt, sich nur durch seine unzutreffenden Schlussfolgerungen erklären lassen. Die Krone dieser Art von Schlussfolgerungen muss ich allerdings darin erblicken, wie Pflüger jetzt auch noch die Untersuchungen von $\mathrm{v}$. Mering und Minkowski gegen die von 0 . Minkowski ins Feld zu führen sucht!

In Gemeinschaft mit v. Mering hatte ich einige partielle Exstirpationen des Pankreas ausgeführt, zunächst nur um zu sehen, ob irgendwelche Nebenverletzungen für das Zustandekommen des Diabetes verantwortlich gemacht werden könnten. Wir liessen zu diesem Zwecke grössere Theile - $1 / 4$ bis $1 / \tilde{s}$ - der Drüse in der Bauchhöhle zurück, und zwar in der Weise, dass die Theile, die bei dem einen Versuche zurückgebliebèn waren, bei dem nächsten entfernt wurden. So mussten die Nebenverletzungen, die überhaupt in Betracht kommen konnten, in dem einen oder dem anderen Falle sich bemerkbar machen. Das Ausbleiben des Diabetes in allen diesen Fällen schien uns zu beweisen, dass es nur darauf ankam, ob überhaupt noch functionirendes Pankreasgewebe erhalten blieb oder vollständig fehlte.

Bei der weiteren Verfolgung dieser Frage suchte ich dann zu ermitteln, wieviel eigentlich von dem Pankreasgewebe erhalten bleiben muss, damit der Ausfall dieser Drüse sich nicht in einer Störung des Zuckerverbrauchs bemerkbar mache. Ich fand, wie Pflüger ganz richtig citirt, dass unter gewissen Verbältnissen "auch nach partieller Pankreasexstirpation eine mehr oder weniger erhebliche Zuckerausscheidung im Harne zu Stande kommen kann." Ich gab genauer an, welcher Art diese Verhältnisse waren: Ich erwähnte, dass kleinere Theile der Drüse - $1 / 12$ bis $1 / 15$ nicht immer ausreichten, um die hier in Betracht kommende Pankreasfunction in vollem Umfange zu erfullen. Ich wies darauf hin, dass es nicht allein auf die Gröss e des zurückgebliebenen Drüsenstückes ankommt, sondern viel mehr noch auf seine $\mathrm{Er}$ nährungs- und Circulationsverhältnisse. Ich führte Beispiele an, um zu zeigen, dass Vereiterung und Nekrose des zurückgelassenen Stückes die schwerste Form des Diabetes zur Folge hatte, während bei fortschreitender Sklerosirung dieser Drüsenreste leichtere Formen des Diabetes sich bemerkbar machen konnten, 
und ich erblickte in diesen Beobachtungen - wie ich auch jetzt noch glaube, mit Recht - einen weiteren Beweis für die besondere Rolle der Pankreasfunction im Zuckerstoffwechsel.

Es handelte sich also auch hier nur um eine Ergänzung der früheren Beobachtungen. Wie man sagen kann, ich bätte irgendeine der früher gemachten Angaben "widerrufen", ist mir einfach unbegreiflich!

Besonders illustrirt wird aber die Auffassung von Pflüger dadurch, dass sie ihn dazu führt, zu folgern, der operative Eingriff in den Versuchen von $O$. Minkowski sei mangelhafter ausgeführt worden, als in den Versuchen von v. Mering und Minkowski. Ich darf demgegenüber versichern: der 0 . Minkowski, der bei den von ihm in Gemeinschaft mit v. Mering veröffentlichten Versuchen die $O$ perationen ausgeführt hat, ist derselbe $O$. Mink ow ski, der später die Untersuchungen über den Pankreasdiabetes allein fortgesetzt hat. Höchstens hat er im Laufe der Zeit durch die Uebung etwas mehr Geschicklichkeit in der operativen Technik erworben.

Die "Thatsache", die Pflüger hier "entgegentrat", berubte wahrlich auf einem argen "Trugschlusse"!

Pflüger sagt übrigens, ich hätte ihm „schlechte Versuche und Trugschlüsse" vorgeworfen. Ich wüsste nicht, wo ich von "schlechten Versuchen" gesprochen hätte. Den Ausdruck habe ich niemals gebraucht, und ich lege Werth auf Correctheit des Ausdrucks. Ich sprach in einem bestimmten Zusammenhange von Versuchen, die „für die Entscheidung der hi e r in Betracht kommenden quantitativen Verhältnisse nicht geeignet" waren. Das ist doch etwas ganz anderes! Und ich habe doch auch keinen Zweifel darüber gelassen, was ich gemeint habe.

Ich gebe ohne Weiteres zu, dass die Beobachtungen an Thieren, die nach partieller Pankreasexstirpation diabetisch werden ${ }^{1}$ ),

1) Pflüger findet es angemessen, diesen nach partieller Pankreasexstirpation auftretenden Diabetes als "Sandmeyer'schen Diabetes" zu bezeichnen. Ich darf vielleicht demgegenüber darauf hinweisen, dass ich über das Auftreten eines Diabetes nach partieller Pankreasexstirpation schon im Januar 1890 (Centralbl. f. klin. Medicin 1890 Nr. 5) Mittheilung gemacht babe. Die Arbeit von Sandmeyer datirt aus dem Jahre 1892. Vor Sandmeyer batten auch schon Lépine und namentlich Hédon über Glykosurie nach partieller Pankreasexstirpation berichtet. 
für die Entscheidung gewisser Fragen durchaus brauchbar sind. So vermochte namentlich Lüthje, wie auch Pflüger, an solchen Thieren, weil sie länger am Leben bleiben, in einer selbst für die grössten Zweifler überzeugenden Weise darzuthun, dass bei ausschliesslicher Eiweissnahrung im thierischen Organismus Zucker gebildet werden kann. Allerdings glaube ich, dass dieses bereits durch meine eigenen Beobachtungen zur Genüge erwiesen war. Immerhin konnte eine Bestätigung „in noch ausgedehnterem Maasse" nur erwünscht sein. Nicht geeignet aber sind solche Versuche, um die Grösse der maximalen Zuckerbildung festzustellen. Denm nach partieller Exstirpation tritt der Pankreasdiabetes in der Regel nicht in seiner böchsten Intensität auf; auch kann die Intensität dieses Diabetes grösseren Schwankungen unterworfen sein, weil die Function des zurückgebliebenen Drüsenrestes manchen unübersehbaren Einfüssen unterliegen kann. Ebenso sind Versuche an Thieren mit Totalexstirpationen, wenn diese Thiere an Eiterungsprozessen leiden, nicht geeignet, über die Grösse der maximalen Zuckerbildung Aufschluss zu geben, weil erfahrungsgemäss auch durch solche complicirende Erkrankungen die Intensität der Glykosurie beeinflusst werden kann.

Indem ich von „der Grösse der max i mal en Zuckerausscheidang bei reiner Fleischnahrung" sprach, glaubte ich vor einer Missdeutung geschützt zu sein. Es geschah daher durchaus nicht, wie Pflüg er sagt, „um den Mangel der Begründung seiner absolut falschen Behauptung dem Leser weniger anstössig erscheinen zu lassen", dass ich hinzufügte: „im Uebrigen wird diese Frage an der Hand von weiteren Untersuchungen noch zu discutiren sein." Vielmehr wollte ich mit diesen Worten nur meiner Ueberzeugung Ausdruck geben, dass es sich hier um eine complicirte und wichtige Frage handelt, die sich nicht mit einer fluchtigen Bemerkung erledigen liess. Ich verwies überdies ausdrücklich auf die nähere Begründung, die bereits in meiner früheren Arbeit gegeben war, und ich behielt mir nur vor, bei Gelegenheit der Publication von neuen Untersuchungen auf diese Frage noch einmal eingehender zurückzukonmen.

Die erneuten Angriffe von Pflüger haben mich veranlasst, nicht auf den Abschluss jener Untersuchungen zu warten, sondern schon jetzt hier auf die Frage einzugehen, deren Klarstellung in dieser Abhandlung mir, offen gestanden, mehr am Herzen liegt als die Zurückweisung der Pflüg e r'schen Vorwürfe. Es ist dieses die 
Frage, die auch Pflüger als eine der wichtigsten des Gebietes bezeichnet, die Frage nach dem Ursprung des im Organismus gebildeten Zuckers beim Pankreasdiabetes.

Dass im Organismus diabetischer Thiere Zucker a us Substanzen entstehen kann, die keine Kohlenhydrate sind, darf, wie wir gesehen haben, gegenwärtig als unbestrittene Thatsache bezeichnet werden. Die Sicherheit der Erkenntniss haben wir hier zweifellos in der Hauptsache den Untersuchungeu über die Folgen der Pankreasexstirpation zu verdanken. Ess ist für die Sache gleichgültig, ob man das grössere Verdienst hierbei den ersten Beobachtern des experimentellen Pankreasdiabetes zuschreiben will, oder denjenigen Autoren, die später in noch überzeugenderer Weise die Versuche wiederholt haben.

Die Annahme, dass der im Organismus neu gebildete Zucker speciell den Eiweisssubstanzen seinen Ursprung verdanke, fand, wie erwähnt, eine Hauptstütze in der von mir gemachten Beobachtung, dass unter gewissen Bedingungen die im Harne der diabetischen Hunde ausgeschiedenen Zuckermengen in einem bestimmten Verbältnisse $z u$ der ausgeschiedenen Stickst offmenge standen. Dieses von mir mit $D: N$ bezeichnete Verhältniss betrug bei meinen Versuchen „im Durchschnitt ungefähr" $2,8: 1$.

Einzelne Autoren nannten dieses die "Minkowski'sche Zahl“. Doch muss ich es als eine unverdiente Ehre bezeichnen, wenn Pflüger von der "Minkowski'schen Lehre, dass das Eiweiss die Quelle des diabetischen Zuckers.

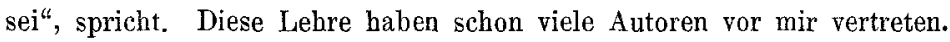

Gegen diesen Quotienten $D: N$ richten sich nun zunächst die wichtigsten Argumente von $\mathrm{Pflüger}$, der seine Betrachtungen mit der Bemerkung abschliesst: „Mag aber O. Minkowski das zugeben oder nicht, seine den Quotienten $D: N$ betreffenden Lehren bleiben als Irrthümer bestehen."

Hier muss ich nun vor Allem den Einwand erheben, dass Pflüger mir wieder eine Auffassung zuschreibt, die ich niemals vertreten habe. Ich will ihm hieraus keinen besonders schweren Vorwurf machen, denn offenbar liegt hier ein Missverständniss vor, indem mich Pflüger für die Vorstellungen verantwortlich macht, die andere Autoren mit dem Quotienten $D: N$ verknüpft haben. Ich habe schon längst das Bedürfniss em- 
pfunden, meine Auffassung des Quotienten $D: N$ klarer zu präcisiren, und ergreife gerne die mir hier dazu gebotene Gelegenheit.

Pflüg er meint den „Satz Minkowski's“ widerlegt zu haben, „dass der Quotient $D: N$ ein unveränderlicher Werth sei, der nur 2,8 betrage". Er führt eine Stelle aus meiner Arbeit wörtlich an, aus welcher diese Behauptung hervorzugehen scheint. Leider hat er den vorhergehenden Satznicht beachtet, welcher lautet: "Es ergab sich nun, dass bei den Thieren, welche den operativen Eingriff gut überstanden haben, und bei welchen sicher keine Reste von functionirendem Pankreasgewebe zuruckgeblieben sind, die Intensität des Diabetes lange Zeit eine vollkommen gleichmässige bleiben kann". Dann erst heisst es bei mir weiter: "Es zeigte sich dieses zunächst darin, dass bei Ausschluss von Kohlehydraten aus der Nahrung die im Harne enthaltene Zuckermenge in einem ganz bestimmten Verbältniss za der ausgeschiedenen Stickstoffmenge stand, d. h. also von der Menge der im Organismus zersetzten Eiweisssubstanzen abhängig war". Ist hier wirklich von einem "unveränderlichen" Werthe, der "nur" 2,8 beträgt, die Rede?

Pflüger sagt an einer anderen Stelle seines Glykogenwerkes (S. 318): „O. Minkowski berichtet selbst, dass doch auch grössere Abweichungen vorkommen, von 0,41 bis 7,71 , und das ist ein bischen viel für einen Werth, der für eine Constante erklärt wird“. Das ist zweifellos richtig! Aber - ich meine, der nächste Schluss, der sich daraus ergibt, ist doch einfach der: 0 . Minkowski hat eben keineswegs diesen Werth unter allen Unständen als eine „Constante" angesehen!

Es sei hier zunächst nochmals darauf hingewiesen, dass das, was ich thatsächlicb behauptet habe, wie bereits erwähnt, zuerst von Lüthje und jetzt auch von Pflüger selbst durchaus bestätigt wurde, indem Letzterer beobachtete, dass bei einem Hunde, dessen Zuckerausscheidung nicht mehr aus dem Kohlehydratbestande des Körpers erklärbar war, und der eine Reihe von Monaten mit fettund kohlehydratfreiem Eiweiss ernährt wurde, „während eines sehr langen Zeitraumes die Ausscheidung des Zuckers und des Stickstoffs streng proportional war". Die ganze Differenz zwischen unseren Angaben reducirt sich also eigentlich nur darauf, dass bei Pflüger der Quotient $D: N$ kleiner ist und in dieser Periode der Constanz nur 2,2 beträgt. Ueber diese Differenz, meinte ich, „wird zu discu- 
tiren sein". Dann wird zu erörtern sein, wie man die auffallende Abhängigkeit der Zuckermenge von dem Stickstoffumsatz deuten könnte.

Wie die Grösse des Quotienten $D: N$ unter verschiedenen Verhältnissen sowohl nach oben wie nach unten sich von der Zahl 2,8 sehr weit entfernen kann, habe ich in meiner Arbeit sehr ausführlich erörtert. Die ganze Polemik Pflüg er's, soweit sie darzuthun sucht, dass "von einer Constanz des Quotienten $D: N$ im Sinne Minkowski's keine Rede sein kann", ist daher mir gegenüber eigentlich gegenstandslos. Dass der höhere Quotient, den ich in vielen Fällen in den ersten Tagen nach der Pankreasexstirpation beobachtet habe, auf die rasche Ausschüttung des im Organismus abgelagerten Glykogenvorraths zurückgefübrt werden durfte, wird wohl auch Pflüger nicht bestreiten. Nach Phloridzininjectionen habe ich bei diabetischen Hunden den Quotienten $D: N$ vorübergehend bis auf 10,8 ansteigen sehen. Es mag dahingestellt bleiben, ob die Vermuthungen, die ich zur Erklärung dieser Erscheinung ausgesprochen habe, zutreffend sind. Jedenfalls liegen bei der Phloridzinvergiftung ganz besondere Verhältnisse vor, und es kann unmöglich gegen mich geltend gemacht werden, dass auch audere Autoren nach der Phloridzinvergiftung höhere Werthe für den Quotienten $D: N$ gefunden haben. Dass vollends Lüthje nach Fütterung mit Glycerin und Blutserum, Embden und Salomon nach Zufuhr von Alanin, Asparagin und Glykokoll ein Ansteigen der Zuckerausscheidung beobachtet haben, ist gewiss etwas, was mit den von mir vertretenen Anschauungen leichter in Einklang zu bringen ist, als mit den Ansichten Pflüger's. Es ist bemerkenswerth, dass, während Pflüger die genannten Autoren gegen mich ins Feld führt, diese Autoren selbst ihre Untersuchungen eher als Bestätigungen, denn als Widerlegungen meiner Angaben aufgefasst haben.

Es scheint aber auch, als ob Pflüger neuerdings schon darauf verzichtet hat, die höheren Werthe von $D: N$ gegen meine „irrige Lehre" geltend zu machen, offenbar, weil er selbst unter den von mir angegebenen Bedingungen niemals einen böheren Werth beobachtet hat. Er hebt jetzt in seiner "Antwort" nur hervor, dass er "bewiesen“ habe, dass „am Pankreasdiabetes leidende Hunde, welche in ihrem Körper keinen Rest von Kohlehydraten beherbergen, und die nur mit Eiweiss ernährt werden, einen Quotienten 
$D: N$ baben, der nicht constant ist und viel kleiner als 2,8 sich erwies".

Einen solchen kleineren Wertb, der im Mittel 2,17 betrug, hat Pflüger ${ }^{1}$ ) am 10. bis 15 . Tag nach der Totalexstirpation bei einem Hunde beobachtet, der nach der Operation überhaupt keine Nahrung mebr erhielt und am 17. Tag in Folge von "mehrfachen Perforationen des Duodenums und Geschwüren der Schleimhaut in nächster Nachbarschaft der Durchbohrungen zu Grunde ging". Da Pflüg er diesen Versuch „als besonders lehrreiches Beispiel" dafür anführt, „wie in allen Fảllen nach einer wirkilichen Totalexstirpation sich grundsätzlich der Verlauf des Diabetes gestaltet hat", und da er den ermittelten Quotienten auch noch durch fetten Druck besonders hervorhebt, so hatte ich geglaubt, dass Pflüger auch auf diesen Versuch einen gewissen Werth legte. Weil ich nun in mejner Arbeit ausfübrlich dargethan hatte, dass der Quotient zu sinken pflegt, wenn die Thiere an complicirenden Erkrankungen zu Grunde gehen, so durfte ich diesen Versuch als "für die Entscheidung der hier in Betracht kommenden quantitativen Verhältnisse durehaus nicht ge eignet " zurückweisen. Jetzt betont Pflüger, dass er "gerade solche Versuche für ungeeignet zur Beurteilung des Quotienten $D: N$ ausdrücklich erklärt habe, bei denen complicirende Eiterungen das Leben verkürzen". Hier kann ich also wieder nur eine er. freuliche Uebereinstimmung zwischen Pflüger und mir constatiren. Es war nur aus der Darstellung Pflügers nicht recht ersichtlich, dass er nicht nur meine, sondern auch seine Versuche dieser Art für die Entscheidung der vorliegenden Frage nicht für geeignet hielt!

Unbegreiflich ist es mir unter diesen Umständen nur, dass Pflüg er jetzt neuerdings in der Nachschrift za seiner, Antwort" die Beobachtungen von Almagia und Embden ${ }^{2}$ an Hunden, denen das Pankreas gleichfalls total exstirpirt war, zum Zeugniss gegen mich anführt. Diesen Versuchen gegenüber gelten doch die gleichen Finwände, wie gegenüber allen übrigen Totalexstirpationen! Mir scheint es im Gegentheil bemerkenswerth, dass gerade bei einem Versuche der genannten Autoren, in welchem das Thier die Operation offenbar gut überstanden hatte, der Quotient $D: N$ zwiseben 2,54 und 2,95 schwankte und im Mittel 2,72 betrug. Diese Autoren selbst betrachten ihre Beobachtungen auch durchaus nicht als eine Widerlegung meiner Angaben.

1) Glykogen S. 490.

2) Zeitschr. f. d. ges. Biochemie (H ofm e ister's Beitr.) Bd. 7 S. 298. 1905. 
Dasselbe gilt für die von Pflüger jetzt auch gegen mich angeführten Beobachtungen von $L \ddot{u} t h \mathrm{e}^{1}$ ), der das Sinken der Zuckerausscheidung bei erhöhter Tmgebungstemperatur nur auf eine Verminderung der Zuckerproduction zurückführt. Auch in dieser Auffassung befinde ich mich, im Gegensatze zu Pflüger, in Uebereinstimmung mit Lüthje.

Das Hauptbeweismittel erblickt aber jetzt Pflüger in seinen Beobachtungen an den Hunden, bei denen nach parti elle r Pankreasexstirpation erst nachträglich mit der Verödung des zurückgebliebenen Pankreasstückes der Diabetes hervortritt. Ich will hier nicht davon sprechen, wie merkwürdig es ist, dass bei diesen Versuchen die den Diabetes verursachende "Nervenreizung" nicht wie nach der Totalexstirpation unmittelbar nach dem operativen Eingriffe, sondern erst allmählich mit der fortschreitenden Degeneration des zurückgebliebenen Drüsenrestes auftritt. Vielleicht könnten viele mit mir gerade hierin einen Beweis für eine besondere Function der Drüse beim Zuckerumsatz erblicken. Diese Versuche sind es aber gerade, welche Pflüg er dazu dienen "festzustellen", dass "der Quotient $D: N$ mit Werthen unter 1 anfängt, dann zu. Werthen wächst, die annähernd 2,2 betragen, um später wieder unter 2 herabzugehen and sich der 1 zu nähern*.

Demgegenüber muss ich leider dabei beharren, dass gerade diese Versuche für die Fntscheidung der „hier in Betracht kommenden quantitativen Verhältnisse" a m allerwenigsten geeignet sind! Denn bei diesen Versuchen wird die Function der Drüse nicht völlig ausgeschaltet, sondern nur allmählich in zunehmendem Maasse beeinträchtigt. Der zurückbleibende Drüsenrest functionirt noch bis zu einem gewissen Grade weiter, wenn schon Zucker im Harne auftritt, und die Function dieses Drüsenrestes kann den mannigfachsten Einflüssen unterliegen, je nach den Ansprüchen, die an diese Function gestellt werden, je nach den Einwirkungen verschiedenster Art, denen der gesammte Organismus des Versuchsthieres, oder das zurückgebliebene Drüsenstück selbst unterworfen ist. Daher ist die Intensität des Diabetes bei diesen Versuchen eine schwankende, und sie erreicht nicht ihren höchsten Grad, solange überhaupt noch functionirende Drüsenelemente vorhanden sind.

Der Beweis für diese meine Behauptung ist leicht zu führen. Man braucht nur bei einem solchen Thiere, wenn es schon diabetisch

1) Verhandl. d. XXII. Congresses f. innere Medicin 1905 S. 268. 
ist, den Drüsenrest zu entfernen. Dann zejgt es sich, dass die Intensität des Diabetes noch anzusteigen vermag. Allerdings ist es nicht leicht, ein solches bereits diabetisches Thier über die Folgen des erneuten operativen Eingriffs hinauszubringen. Aber es ist dieses durchführbar, wenn man das Drüsenstück frühzeitig unter die Haut transplantirt hat, so dass man nicht noch einmal die Bauchhöhle zu eröffnen braucht, nachdem das Thiere schon diabetisch geworden ist.

Nach meinen Erfahrungen unterliegt es für mich keinem Zweifel, dass die erheblich kleineren und schwankenden Werthe, die Pflüger in den meisten Fällen nach seinen partiellen Exstirpationen beobachtet hat, nur durch die unvollkommene Ausschaltung der Drüsenfunction zu erklären ist. Fraglich könnte es aber erscheinen, ob nicht der grässte von ihm gefundene Werth 2,2 doch vielleicht der maximalen Grösse der Zuckerbildung im diabetischen Organismus entsprechen könnte. $\mathrm{Zu}$ Gunsten einer solchen Möglichkeit könnte vielleicht der Umstand sprechen, dass diese Grösse des Quotienten, nachdem sie erst einmal bei der allmählich wachsenden Intensität des Diabetes erreicht war, in dem betreffenden Versuche auffallend lange constant blieb. Ausserdem aber gibt Pflüg er für diesen Werth des Quotienten $D: N$ eine Erklärung, die durchaus beachtenswerth ist, weil sie die Möglichkeit eröffnet, die eigenartigen, hier zu Tage tretenden quantitativen Beziehungen unserem Verständniss näher zu bringen:

Pflüger führt aus, dass man die chemische Mechanik der Zuckerbildung aus den stickstoffhaltigen Substanzen sich so vorstellen könnte, dass durch die Desamidirung zunächst je eine $\mathrm{NH}_{2}-\mathrm{C}-\mathrm{I}$ Gruppe in eine $\mathrm{OH}-\stackrel{1}{\mathrm{C}}-\mathrm{H}$ Gruppe übergeführt, und dann aus solchen Oxymethylengruppen durch Polymerisirung und geringe Atomverschiebung die Glykose gebildet würde. Dann käme auf je 1 Atom Stickstoff 1 Molekül einfachstes Kohlehydrat. Unter der Voraussetzung, dass "das Eiweiss trotz der sehr versehiedenen Bindung der $\mathrm{N}$ - und $\mathrm{C}$-Atome allen $\mathrm{N}$ in der Form $\mathrm{NH}_{2}-\mathrm{C}-\mathrm{H}$ liefern könnte" - einer Voraussetzung, die übrigens, wenn man "fast allen" sagte, wohl obne weiteres zulässig sein dürfte ${ }^{1}$ ) würde sich daraus für das Verhältniss der aus dem Eiweiss gebildeten Glykose zum Stickstoff folgende Berechnung ergeben:

1) Vgl. auch weiter unten S. 56 . 


$$
\frac{\mathrm{HCOH}}{\mathrm{N}}=\frac{30}{14}=2,15=\frac{D}{\bar{N}}
$$

Trotz der auffallenden Congruenz dieser Zahl mit dem von ihm ermittelten Quotienten 2,2 glaubt aber Pflüger hieraus einen Beweis für die Zuckerbildung aus $\mathrm{Ei}$ iw is nicht ableiten zu können, weil er dem Stickstoff auch einen bestimmenden Einfluss auf die Menge des aus den Fetten gebildeten Zuckers zuschreiben zu dürfen glaubt.

Wir werden auf die Betrachtungen, die an diese Hypothese Pflüger's angeknüpft werden können, noch weiter unten zurückzukommen haben. Zuvor aber wird die Frage zu prüfen sein, wie weit die zahlenmässigen Beziehungen, die sich aus der soeben angeführten Berechnung $P f l u ̈ g$ er's ergeben, mit dem von mir ermittelten Werthe für den Quotienten $D: N$ in Einklang gebracht werden könnten.

Dabei kann ich zunächst ohne Weiteres zugeben, dass die Zahl 2,8 für das Verhältniss der im Organismus beim Pankreasdiabetes neu gebildeten Kohlehydrate zum Stickstoff sicher $\mathrm{zu}$ gross ist. Ich kann dieses ohne jede Selbstüberwindung zugeben, da ich jener Zahl niemals eine solche Bedeutung beigelegt habe.

Bei meinen Untersuchungen (1. c. S. 12 ff.) kam es mir vor Allem darauf an, festzustellen, welches die grösste Zuckermenge ist, die bei reiner Fleischnahrung im Harne der diabetischen Thiere zur Ausscheidung gelangt. Denn es handelte sich zunächst darum, ein Urtheil über die Intensität des nach der Pankreasexstirpation auftretenden Diabetes zu gewinnen, darüber, ob überhaupt noch nach der Pankreasexstirpation Zucker im Organismus verbraucht werden kann, oder ob die Mitwirkung dieses Organes für den normalen Ablauf des Zuckerstoffwechsels unumgänglich nothwendig ist. Ich betonte, dass selbstverständlich die absolute Grösse der ausgeschiedenen Zuckermenge einen Maassstab für die Intensität des Diabetes nicht abgeben könnte, dass "in dieser Hinsicht nur das Verhältniss der im Harne auftretenden Zuckermenge zu der im Organismus entstandenen und in der Nahrung zugeführten Menge entscheidend sein" könnte.

Die Versuchsanordnung, die sich nun hieraus ergab, war eine sehr einfache: erst musste festgestellt werden, wie gross die Zuckerausscheidung bei einer bestimmten Grösse der Fleischnahrung war, und dann sollten der gleichen Nahrung bestimmte Mengen von 
Kohlehydraten hinzugefügt werden, um ihren Einfluss auf die Zuckerausfuhr im Harne zu prüfen.

Die Schwierigkeiten, die sich der Durchführung dieser Versuche entgegenstellten, habe ich in meiner Arbeit eingehend geschildert und dabei auch zur Genüge hervorgehoben, wie vorsichtig man in Anbetracht dieser Schwierigkeiten bei der Beurtheilung der Resultate sein musste.

Es wurden selbstverständlich für diese Versuche Thiere gewählt, welche die Operation möglichst gut überstanden hatten, und bei denen man nach dem ganzen Verlauf annehmen durfte, dass der Diabetes auf der gleichmässigen Intensität seines Höhestadiums beharrte.

Bei diesen Thieren trat nun, als sie mit reiner Fleischnahrung gefüttert wurden, in sehr auffallender Weise die Abhängigkeit der Zuckerausscheidung" von der Grösse des Stickstoffumsatzes hervor. Ich habe in meiner Arbeit dieses in einer Tabelle zum Ausdruck gebracht, in welcher die einzelnen Versuche nach dem Körpergewicht der Thiere geordnet waren. Eindrucksvoller treten vielleicht die auffallenden Beziehungen zwischen Zuckerausscheidung und Stickstoffausfuhr hervor, wenn man diese Tabelle nach der Grösse der ausgeschiedenen Stickstoffmenge ordnet:

Es entspricht dann

einer Stickstoffausscheidung von $4,20 \mathrm{~g}$ eine Zuckerausscheidung von $12,4 \mathrm{~g}$

\begin{tabular}{|c|c|c|c|c|c|c|}
\hline$"$ & $n$ & $" 4,88 \#$ & $"$ & $"$ & $n$ & 12,8 \\
\hline$"$ & $"$ & $" \quad 5,45 n$ & $n$ & $"$ & " & $14,5 n$ \\
\hline$"$ & $"$ & $" 5,46 "$ & $"$ & $"$ & $"$ & 15,1 " \\
\hline$"$ & $\eta$ & $" 5,95 \#$ & $n$ & $n$ & $\because$ & $16,0 "$ \\
\hline$"$ & $"$ & $" 6,30 "$ & $"$ & $"$ & $"$ & 19,1, \\
\hline$"$ & $"$ & $" 6,40 "$ & $"$ & $"$ & $\eta$ & 20,2 , \\
\hline$"$ & $"$ & $" 6,70 "$ & $"$ & $"$ & $"$ & $20,2 "$ \\
\hline$"$ & $"$ & $" 8,73$ & $"$ & $"$ & $"$ & 24,4 , \\
\hline$"$ & 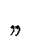 & $\# 10,12 "$ & $n$ & $"$ & $"$ & $27,3 n$ \\
\hline$\eta$ & $"$ & $" 11,10 "$ & $"$ & $"$ & $n$ & $30,0 "$ \\
\hline$\eta$ & $"$ & $" 11,90 "$ & $»$ & $n$ & $n$ & 34,3, \\
\hline$\eta$ & $"$ & $" 12,45 "$ & $"$ & $"$ & $"$ & $37,0 "$ \\
\hline$"$ & $"$ & $" 12,76 "$ & $"$ & $"$ & $"$ & 34,8 , \\
\hline$\pi$ & $"$ & $" 13,73$ & $"$ & $"$ & " & $40,0 "$ \\
\hline$"$ & $n$ & $" 14,05 n$ & $n$ & $"$ & $"$ & 42,0 , \\
\hline$"$ & $"$ & $" 14,26 "$ & $n$ & $"$ & $"$ & $43,2 "$ \\
\hline$"$ & $"$ & $" 14,40$, & $"$ & $"$ & $n$ & $44,7 "$ \\
\hline$"$ & $"$ & $" 17,45 \#$ & $"$ & $n$ & $n$ & 54,0 \\
\hline
\end{tabular}


einer Stickstoffausscheidung von $17,50 \mathrm{~g}$ eine Zuckerausscheidung von $53,6 \mathrm{~g}$

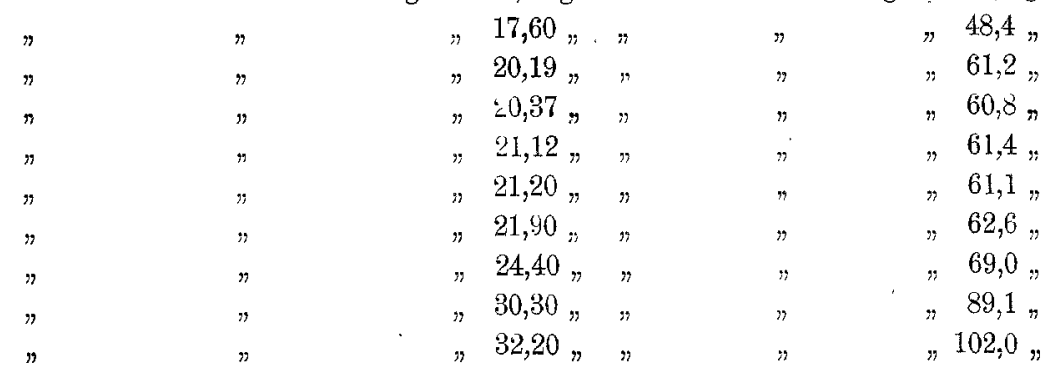

Man sieht, wie hier eine fast vollkommene Proportionalität zwischen der Grösse der Zucker- und der Stickstoffausscheidung zu Tage tritt. Das, was mir an diesem Ergebnisse zunächst am bemerkenswerthesten erschien, war nun der Umstand, dass das Verhältniss von Zucker zu Stickstoff sich von der absoluten Grösse der ausgeschiedenen Mengen vollkommen unabhängig erwies. Ich ging nun von folgender Erwägung aus: Es ist eine dem Arzte geläufige Vorstellung, dass die Unzulänglichkeit einer geschädigten Function um so mehr hervortritt, je grössere Anforderungen an diese Function gestellt werden. Es steht das nicht im Widerspruche mit der Thatsache, dass auch die Summe der Leistungen einer solchen geschädigten Function wachsen kann, sobald die Anforderungen erhöht werden. Speciell auch bei deu mittelschweren Fälten des Diabetes beim Menschen ist es eine ganz gewöhnliche Erscheinung, dass der Bruchtheil der im Harne wieder ausgeschiedenen Zuckermenge um so grösser wird, je grösser die absolute Menge des dem Organismus zur Verfügung stehenden Zuckers wird. Ein Diabetischer, der eine gewisse Menge Zucker, sagen wir beispielsweise $25 \mathrm{~g}$, noch vollkommen zu verbrauchen vermag, scheidet nach Zufuhr von $50 \mathrm{~g}$ vielleicht $10 \mathrm{~g}$ im Harne aus und nach Zufuhr von $100 \mathrm{~g}$ bis zu $40 \mathrm{~g}$. Er verwerthet also $\mathrm{z}$ war bei steigender Zufuhr immer mehr, $25-40-60 \mathrm{~g}$; der ausgeschiedene Bruchtheil wächst aber von $1 / 8$ bis $1 / 5$ und $2 / 5$. Dass nun, im Gegensatze dazu, auf der Höhe des Pankreasdiabetes - wemn auch nur für längere Zeiträume - das Verhältniss zwischen der ausgeschiedenen Zucker- und Stickstoffmenge gewahrt blieb, unabhängig von der Grösse der Versuchsthiere und unabhängig von der absoluten Grösse der Zuckermenge, das, meinte ich daher, würde "am leichtesten verständlich" sein, wemn man annimmt, dass "die gesammte Menge des im Körper aus Eiweiss gebildeten Zuckers nach der Pankreasexstirpation im Harne aus- 
geschieden wird". Das heisst also: die in gleichem Maasse hervortretende Unzulänglichkeit der Leistungen gegenüber geringfügigen, wie gegenüber höheren Anforderungen könnte man sich am ehesten erklären, wenn man annimmt, dass es sich nicht blos un eine Schädigung, sondern um einen vollständigen Ausfall einer bestimmten Function handelt.

Der Ausdruck "würde am leichtesten verständlich sein " zeigt schon, wie weit ich davon entfernt war, dieses als einen wirklichen Beweis anzusehen. Ich habe auch die Schwierigkeiten einer sicheren Beweisführung noeh weiterhin ausführlich erörtert und auch noch andere Beobachtungen angeführt, die es mir wahrscheinlich machten, dass nach vollständiger Entfernung der Bauchspeicheldrüse der nor $\left.\mathrm{male}^{\mathbf{1}}\right)$ Zuckerverbrauch im Organismus überhaupt nicht mehr von Statten gehen kann. Für sicher bewiesen halte ich es auch jetzt noch nicht, dass ohne Mitwirkung des Pankreas eine Verwerthung des Zuckers für die Leistungen des Organismus überhaupt nicht mehr möglich ist. Ich gebe gerne zu, dass eine solche Annahme meiner subjectiven Ueberzeugung entspricht. Ich weiss aber sehr wohl eine subjective, intuitiv erworbene Ueberzeugung von einer objectiven Beweisführung zu unterscheiden. Es wird noch vieler mühevoller Arbeit bedürfen, um über die Bedeutung der Pankreasfunction für den Zuckerverbrauch sicheren Aufschluss zu erhalten.

Doch nicht von dem Wesen des Pankreasdiabetes und den Vorgängen beim Zuckerverbrauch, sondern nur von der Zuckerbild ung im Organismus der diabetischen Thiere soll hier zunächst die Rede sein. Ich habe Vorstehendes nur ausgeführt, um zu zeigen, welche Bedeutung, für mich ursprünglich die Bestimmung des Quotienten $D: N$ gehabt hat. Es ist hiernach wohl ohne Weiteres

1) Es wäre hier allerdings eine Einschränkung zu machen: man könnte sich denken, dass neben dem für die Hauptmasse jedenfalls ausschliesslich in Betracht kommenden Modus der Zuckerverwerthung im Organismus, bei dem die Mitwirkung des Pankreas unerlässlich ist, noch andere Möglichkeiten für den Verbrauch von Zucker gegeben sein könnten, die durch die Pankreasexstirpation nicht beeinflusst werden. Dann müsste man aber annehmen, dass die verschiedenen Reihen von Vorgängen unabhängig von einander verlaufen, und dass jedenfalls ein anderer Modus für den ersten nicht eintreten kann, wenn die Function des Pankreas ausfällt. Vorläufig sind aber keine Thatsachen bekannt, auf die sich eine soiche Auffassung stiutzen könnte. 
klar, dass es für die zunächst ins Auge gefasste Frage nur auf den maximalen Werth dieses Quotienten ankam. Wenn ich daher auch von der Annahme sprach, „dass in den ermittelten Zahlen das Verhältniss Ausdruck findet, in welchem im Organismus die Zuckerbildung aus Eiweiss von Statten geht", so habe ich keineswegs behauptet, dass jene Zahlen dieses Verhältniss genau wiedergeben, und dass der von mir gefundene Quotient genau der Zuckermenge entspricht, die unbedingt bei der Zersetzung der Eiweisssubstanzen im Organismus entstehen muss. Im Gegentheil, ich bemerkte ausårücklich, dass „wir einstweilen kein sicheres Urtheil über die Grösse der Zuckerbildung aus Eiweiss haben“, dass "es noch keineswegs sicher ist, dass stets und unter allen Umständen die gleichen Mengen von Zucker aus einer gegebenen Menge von Eiweisssubstanzen entstehen müssen", ja, dass es "noch nicht einmal vollkommen sicher erwiesen" sei, "wie weit diese Zuckerbildung aus Eiweiss als ein normaler Vorgang zu betrachten ist".

Der von mir ermittelte Quotient 2,8 war nun auch für das Verhältniss der maximal im Organismus neu gebildeten Zuckermenge zum Stickstoff insofern etwas zu gross, als das von mir verfütterte Pferdefleisch unzweifelhaft noch präformierte Kohlehydrate enthielt. Da es mir zunächst für meine Zwecke nur darauf ankam, das bei Verfütterung von bestimmten Fleischmengen im Harne ausgeschiedene Zuckerquantum zu kennen, so brauchte ich diese im Fleisch enthaltenen Kohlehydrate nicht besonders in Rechnung zu bringen. Jedenfalls konnten die Mengen des in dem verfütterten mageren Pferdefleisch entbaltenen Glykogens im Vergleich mit den von den diabetischen Thieren im Harne ausgeschiedenen Zuckermengen nur so gering sein, dass ich sie für meine Betrachtungen vernachlässigen zu dürfen glaubte. Ich will aber zugeben, dass eine gewisse Correctur an dem von mir ermittelten Quotienten angebracht werden muss, wenn man nur die Menge der im Organismus neu gebildeten Kohlehydrate ins Auge fassen will.

Wenn Pflüger aber nun sagt: „Es ist kaum zweifelhaft, dass der hohe Quotient $D: N$, den Minkow ski aufgestellt hat, dadurch veranlasst ist, dass das Glykogen, vielleicht auch Glykoside noch am Stoffwechsel betheiligt sind", so ist dem gegenüber zu bemerken, dass der Glykogenvorrath der Versuchsthiere nicht mehr in Betracht kommen konnte, denn dieser Glykogenvorrath sehwindet nach der Totalexstirpation des Pankreas bereits in den ersten Tagen 
bis auf Spuren, und nach meinen Erfahrungen, die von verschiedenen Autoren bestätigt sind, darf der Glykogenvorrath als nahezu erschöpft angesehen werden, sobald das Verhältniss zwischen Zucker und Stickstoff im Harne ein gleichmässiges wird. Was aber die Glykoside betrifft, so können, bei dem jetzigen Stande unserer Kenntnisse, als solche hier im Wesentlichen doch nur die in Eiweissverbindungen enthaltenen Kohlehydratgruppen in Frage kommen. $\mathrm{Ob}$ man die Abspaltung dieser Kohlehydratgruppen auch als "Zuckerbildung aus Eiweiss" bezeichnen will oder nicht, ist schliesslich nur ein Streit um Worte. Dem Sprachgebrauch ent-

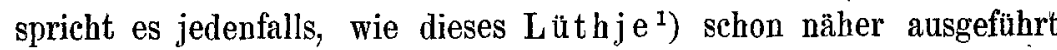
hat, dass man auch die Abspaltung von präformirten Atomcomplexen als eine "Bildung" derselben aus der Muttersubstanz bezeichnet.

Wie gross die Zuckermengen sein mochten, die auf eine $\mathbf{A b}$ spaltung von solchen präformirten Kohlehydratgruppen aus den Eiweissverbindungen zurückgeführt werden konnten, dafür fehlten zu der Zeit, als ich meine Untersuchungen anstellte, alle Anhaltspunkte. Erst die letzten Jahre haben über diese Frage wichtige Aufschlüsse gebracht ${ }^{2}$ ). Aber schon damals war es wahrscheinlich, was heute als sicher gelten darf, dass die in den "Glykoproteïden" enthaltenen Kohlehydratgruppen aicht ausreichen, um die beim Pankreasdiabetes in Organismus entstehenden Zuckermengen zu decken. Ich durfte daher bemerken, dass „die Zuckerbildung im Organismus, wenigstens soweit sie auf Kosten der Eiweisskörper von Statten geht, jedenfalls als ein sehr complicirter Vorgang anzusehen ist, bei welchem wahrscheinlich nicht allein Spaltungen und Oxydationen, sondern auch synthetische Processe eine Rolle spielen" (1. c. S. 24).

Ich glaubte mich damit sogar der Auffassung zu nähern, die Pfl üg e ${ }^{3}$ ) vertreten hatte, als er die Ansicht bekämpfte, der Zucker sei als ein direktes Zerfallsprodukt des Eiweisses anzusehen, und nur die Annahme einer synthetischen Zuckerbildung unter Mitwirkung des lebenden Protoplasmas für zulässig erklärte.

Dabei ging auch ich stets von der Vorstellung aus, dass der Umfang der Zuckerbildung im Organismus in erster Linie durch

1) Deutsch. Arch. f. klin. Medic. Bd. 79 S. 499.1904.

2) Siehe Langstein, Die Bildung ron. Kohlehydraten aus Eiweiss. Ergebnisse der Physiologie Bd. 1 S. 1. 1902.

3) Siehe Pflüger's Arch. Bd. 42 S. 144. 
die Grösse des Zuckerbedarfs geregelt wird - einer Vorstellung, die, obgleich sie hypothetisch ist, wie ich wohl annehmen darf, mit den Anschauungen Pflüger's gut in Einklang steht. Dass aber doch auf der Höhe des Diabetes die Menge des im Harne erscheinenden Zuckers in einem bestimmten Verhältniss zur Stickstoffausfuhr stehen konnte, glaubte ich mir folgendermaassen deuten zu können:

Bei dieser höchsten Intensität des Diabetes ist das Thier überhaupt nicht mehr im Stande, den Zucker in normaler Weise zu verwerthen. Es besteht daher fortwährend ein ungestilltes Bedürfniss nach Zucker. Die "vorhandenen regulatorischen Einrichtungen, die z. B. bei dem durch Muskelarbeit gesteigerten Zuckerbedürfniss das rasche Schwinden des Leberglykogens bewirken", werden daher fortwährend in höchstem Maasse in Anspruch genommen. Der Organismus schöpft aus allen ihm verfügbaren Zuckerquellen, ohne sein Bedürfniss befriedigen zu können. So kommt es, dass, trotz der noch erhaltenen Fähigkeit der Leber, Glykogen zu bilden Pflüger betont ausdrücklich, dass er diese meine Angabe bestätigt hat - eine nennenswerthe Glykogenanhäufung in der Leber nicht mehr zu Stande kommt, weil das entstandene Glykogen sofort wieder in Zucker umgewandelt wird. So kommt es aber ferner, dass das Thier fortwäbrend auch so viel Zucker aus anderen Substanzen bildet, als es überhaupt nur zu bilden vermag. Die Menge des bei Ausschluss von Kohlehydraten aus der Nahrung im Harne ausgeschiedenen Zuckers stellt also das Maximum dessen dar, was das Thier unter den gegebenen Verhältnissen zu bilden im Stande ist. Dass dieses Maximum, solange der Organismus noch auf der Höhe seiner Leistungsfähigkeit steht, in einem bestimmten Verhältniss zur Stickstoffausscheidung steht, deutet darauf hin, dass der Umfang der Zuckerbildung beim Pankreasdiabetes eine gewisse Grenze nicht übersehreiten kann, die durch den Umfang des Eiweissumsatzes bestimmt wird.

Dieses Maximum kann aber nicht immer erreicht werden. Sobald durch complicirende Erkrankungen oder durch den aufs Höchste gediehenen Kräfteverfall auch die Functionen der bei der Zuckerbildung betheiligten Organe leiden, vermag der Organismus — vielleicht handelt es sich hierbei speciell um die Leber - die Zuckersynthese nicht mehr in vollem Umfange zu leisten, und der Abbau der zerfallenden Eiweisssubstanzen vollzieht sich ohne die 
entsprechende Zuckerproduction. Desshalb sinkt der Quotient $D: N$ in den späteren Stadien des Diabetes oder bei dem Auftreten von sehweren complicirenden Erkrankungen.

Beiläufig bemerkt, halte ich es aus gewissen Gründen auch jetzt noch für wahrscheinlich, dass mit der Störung dieser synthetischen Zuckerbildung das Auftreten der Acetonkörper (Oxybuttersäure, Acetessigsäure und Aceton) im Harne in Zusammenhang steht. Diese Substanzen verdanken vielleicht ihre Entstehung gewissen Atomgruppen, die zur synthetischen Umwandlung in Zucker bestimmt sind.

Wie weit diese Vorstellungen auf Hypothesen beruhen, dessen bin ich mir wohl bewusst. Wir bedürfen aber doch nun einmal der Hypothesen, um uns den Zuzammenhang der Dinge zu denten, und um neue Fragestellungen zu finden. Einstweilen scheinen mir diese Hypothesen geeignet, die ermittelten Thatsachen am einfachsten zu erklären. Solange nicht neue Thatsachen beigebracht werden, die mit den hier dargelegten Vorstellungen nicht vereinbar sind, halte ich mich für berechtigt, an diesen Vorstellungen festzuhalten. Die neuerdings von $\mathrm{Pflüger}$ geltend gemachten Anschauungen scheinen sich mir zwanglos mit den hier wiedergegebenen zu vereinigen:

Indem Pflüger die Möglichkeit zugibt, dass für die Ueberführung der Fette in Zucker beim Pankreasdiabetes die Menge des bei der Oxydation des Eiweisses freiwerdenden Stickstoffs von entscheidender Bedeutung ist, hat sich die ganze Streitfrage, ob der Zucker im diabetischen Organismus aus Eiweiss oder Fett entsteht, wesentlich verschoben. Es bleibt als unbestrittene Thatsache, dass der Umfang der Zuckerbildung von dem Umfange des Eiweisszerfalls abhängig ist. $\mathrm{Ob}$ das Material für die Zuckerbildung in den stickstofffreien Bruchstücken des Eiweissmoleküls oder in den Produkten einer oxydativen Spaltung der Fettsäuren zu suchen ist, das ist eine Frage ganz anderer Art, eine Frage, über die unter Umständen kaum zu streiten ist.

Pflüger sagt: "Weil durch Desamidirung aus Aminosäuren, welche Spaltungsprodukte des Eiweissmoleküls sind, Fettsäuren entstehen, wurde mir der Einwand gemacht, dass ich nunmehr die Aminosäuren als Muttersubstanz des Zuckers zugeben müsse." Er bemerkt dem gegenüber: "Ich könnte den Spiess auch umdrehen ... Jedenfalls darf man sagen, dass Diejenigen, welche die aus dem Eiweiss stammenden Fettsäuren als Zuckerquelle ansprechen, die 
aus dem Fett selbst stammenden homologen Fettsäuren grundsätzlich als zur Zuckerbildung gleichberechtigt auch anerkennen müssten." Dieses ist zweifellos ganz richtig! Denn es dürfte in der That kaum einen Unterschied machen, ob eine Oxysäure durch die Desamidirung einer Aminasäure oder durch die Oxydation der entsprechenden Fettsäure entstanden ist. In dieser Beziehung kann von einem Gegensatze der Meinungen auch kaum gesprochen werden.

Ein gewisser Gegensatz besteht allerdings auch jetzt noch. Dieser ist aber nur darin zu finden, dass Pflüger die Zuckerbildung nur aus einer oxydativen Spaltung von hochmolekularen Fettsäuren ableiten möchte, während Andere einen Aufbau von Kohlehydraten aus den Säuren von niederem Molekulargewicht für annehmbar halten. Auf den ersten Blick erscheint nun zwar der von Pflüger angenommene Modus als der einfachere. Aber auch für die andere Möglichkeit sprechen gewisse Beobachtungen, wie die Steigerung der Zuckerausscheidung durch Zufuhr von Aminosäuren niederen Molekulargewichts $u$. A. mehr ( $\mathrm{Neuberg}$ und Langstein, Rudolf Cohn, Friedrich Kraus, Embden und Salomon, Almagia und Embden). Pflüger bezweifelt allerdings die Beweiskraft dieser Beobachtungen, weil er sie in anderer Weise deuten zu können glaubt. Indessen fragt es sich, ob die Hypothese, zu der sich Pflüger jetzt veranlasst sieht, nicht noch gewagter erscheint:

In Anbetracht der unleugbaren Beziehungen der Zuckerkildung zum Stickstoffumsatz hält P flüg er, wie erwähnt, die Voraussetzung für zulässig, dass „bei der Oxydation des Eiweisses im Pankreasdiabetes jedes Stickstoffatom in statu nascendi ein Sauerstoffatom auf die Methylengruppe $\mathrm{CH}_{2}$ der Fette zu übertragen hat." Vielleicht ist dieser Ausspruch nicht ganz wörtlich zu nehmen. Denn es ist ja noch fraglich, ob überhaupt freier Stickstoff bei der Oxydation der Eiweisskörper abgespalten wird, aber dass der gesammte Stickstoff „in statu nascendi“ zur Wirkung kommen soll, wäre doch sicher eine etwas weitgehende Hypothese!

Wir haben wohl allen Grund zu glauben, dass die Hauptmasse des $\mathrm{N}$, sofern sie nicht in höher constituirten Verbindungen zur Ausscheidung gelangt, nur als $\mathrm{NH}_{2}$ abgespalten wird. Wenn nun der abgespaltene Stickstoff bei der Umwandlung der Fette in Zucker eine entscheidende Rolle spielen soll, so müsste man annehmen, dass eine $\mathrm{NH}_{2}$ - Gruppe irgendwie an das $\mathrm{CH}_{2}$ der Fettsäure herantreten 
muss, um die Ueberführung derselben in die Oxymethylengruppe $\mathrm{OHCH}$ oder die nachfolgende Polymerisirung dieser Gruppen zu ermöglichen. Damit aber kämen wir vielleicht gar zu der Vorstellung, dass die Fettsäure erst in eine Aminosäure übergeführt werden müsste, ehe sie als Zuckerquelle dienen kann! Gegen diese Vorstellung würden vielleicht die Vertreter der Anschaunngen, die Pflüger bekämpft, weniger einzuwenden haben als $\mathrm{Pfl}$ üg er selbst.

Vielleicht aber wäre es näherliegend, sich die Abhängigkeit dieser Zuckerbildung von dem Stickstoffumsatze so vorzustellen, dass nicht der abgespaltene Stickstoff an die Fettsäure herantritt, sondern dass umgekehrt die Fettsäuren oder die Producte ihrer oxydativen Spaltung erst an die Eiweissmoleküle herantreten müssten, um durch deren Mitwirkung in Zucker übergeführt zu werden. Man könnte auch die gleiche Möglichkeit für die in den Organismus eingeführten Aminosäuren zulassen, durch welche man beim Pankreasdiabetes ein Ansteigen der Zuckerausscheidung bewirken konnte. Eine solche Auffassung wäre dann vielleicht am ehesten geeignet, die widerstrebenden Meinungen mit einander in Einklang zu bringen: Denn, dass die Fettmenge, die im Organismus abgelagert ist, nur einen aufgespeicherten Vorrath an Spannkräften darstellt, aus welchern der Organismus nur $\mathrm{nach}$ Bedarf schöpft, darin wird wohl Jedermann mit Pflüger übereinstimmen. Es spricht daher in der That nicht mit Bestimmtheit gegen eine Verwerthbarkeit des Fettes bei der Zuckerbildung, wenn die Zufuhr von Fett in der Nahrung weder eine Steigerung der Zuckerausscheidung beim Diabetiker, noch eine Erhöhung des Glykogenvorraths im normalen Organismus bewirken kann. Denn die Fettzufuhr in der Nahrung "vergrössert nur den ohnehin schon unbenutzbaren Vorrath", wie Pflüger ganz richtig bemerkt. Aber der Bedarf des Organismus hängt zweifellos von den Functionen und den Arbeitsleistungen des lebenden Protoplasmas ab. Und so ist es naheliegend, dass es auch das Protoplasma ist, welches die Ueberführung der in unverwerthbarer Form abgelagerten Spannkräfte in verwertbare Atomgruppen vermittelt. Sicher haben wir manchen Grund anzunehmen, dass es gerade die in den Kohlehydraten gegebene Atomgruppirung ist, welche die Verwerthbarkeit des stickstofffreien Materials bei den Arbeitsleistungen des Organismus ermöglicht. Man braucht sich aber dabei den Verbrauch des Zuckers im Organismus nicht so vorzustellen wie eine einfache Verbrennung 
im Ofen. Wenn der Zucker als Kraftquelle dienen soll, dann muss er. wohl an den Stellen verbraucht werden, wo die Kraftleistung vollbracht wird. Desshalb konnte auch die Lehre von der einfachen Zerstörung des Zuckers durch ein im Blute kreisendes glykolytisches Ferment von vorne herein nur unbefriedigend erscheinen. Viel wahrscheinlicher dürfte es sein, dass es gewisse in den Eiweisssubstanzen enthaltene Atomgruppen sind, die bei der Arbeitsleistung aufgebraucht werden - wobei vielleicht neben den stickstofffreien gleichzeitig auch eine bestimmte Menge von stickstoffhaltigen Gruppen abgespalten wird - und dass der Wiederaufbau des Moleküls durch Anlagerung von neuen Atomgruppen erfolgt, durch welche das Protoplasma erst wieder zu neuer Arbeitsleistung befähigt wird. Das Material für diesen Wiederaufbau liefern wohl in erster Linie die präformirten Kohlehydrate der Nabrung, deren Ueberschuss vorübergehend als Glykogen in einer leicht wieder verwerthbaren Form abgelagert wird. Reicht dieser Vorrath nicht aus, dann bildet der Organismus neue Kohlehydratgruppen aus anderen Atomcomplexen. Ob hierzu mebr die stickstofffreien Spaltungsproducte der abgebauten Eiweisskörper oder die Zersetzungsproducte der Fette verwendet werden, mag unentschieden bleiben. Es kann vielleicht beides der Fall sein. Die Hauptsache ist, dass der Umfang dieser Kohlehydratbildung durch die Menge der an dem Process betheiligten Eiweissubstanzen bestimmt wird. Desshalb darf man vielleicht doch davon sprechen, dass das Eiweiss als Quelle des im Organismus gebildeten Zuckers anzusehen ist, selbst wenn man zugibt, dass das Material für diese Zuckerbildung auch aus dem oxydativen Zerfall des Fettes hervorgehen kann. Und in der maximalen Grösse des Quotienten $D: N$ wäre demnach in jedem Falle das Maass für die grösste Menge von Zucker gegeben, die bei dem Zerfall einer bestimmten Menge von Eiweisssubstanzen im Organismus entstehen kann.

Unter der Voraussetzung, dass bei der höchsten Intensität des Yankreasdiabetes die gesammte im Organismus gebildete Zuckermenge wieder im Harne erscheint, würde demnach der von mir ermittelte Werth 2,8 für den Quotienten $D: N$ der grössten Gesammtmenge des Zuckers entsprechen, die bei der Zersetzung einer bestimmten Eiweissmenge im Organismus gebildet werden kann. Wie viel davon auf Rechnung einer Abspaltung von präformirten Kohlehydratgruppen und wie viel auf eine synthetische Bildung. 
neuer Kohlehydrate zu setzen ist, dürfte auch heute noch nicht mit Sicherheit zu entscheiden sein. Nimmt man an - was ja zunächst gewiss etwas Verlockendes hat - dass die quantitative Beziehung zwischen Zuckerne u bildung und Stickstoffumsatz thatsächlich in dem von Pfl üg er aufgestellten Verhältniss $\frac{C H \cdot O H}{N}=2,15$ gegeben ist, so würde die Differenz von 0,65 - soweit sie nicht durch den Glykogengehalt der verfütterten Fleischnahrung bedingt ist - hauptsächlich auf die in den Eiweissverbindungen präformirten Kohlehydratgruppen zurückgeführt werden müssen. Das würde einem abspaltbaren Kohlehydratgehalt der Eiweissverbindungen von in maximo $10 \%$ entsprechen. Es ist dieses eine Menge, die vielleicht für einzelne Eiweisskörper, wie das Ovalbumin, nach den Untersuchungen von Seemann, Blumenthal und Langstein, annehmbar wäre, als Durchschnittswerth für alle beim Stoffwechsel betheiligten Eiweisssubstanzen aber sicher zu gross wäre. Andererseits aber ist $\mathrm{zu}$ berücksichtigen, dass in dem Verhältniss $\frac{\mathrm{CH} \cdot \mathrm{OH}}{\mathrm{N}}$ doch nur die Menge der unter Mitwirkung des Stickstoffs neu gebildeten Oxymethylengruppen ausgedrückt ist. Es könnten aber im Organismus in Atomcomplexen, die noch keine Kohlebydrate sind, wie im Glycerin, Lecithin etc., schon präformirte $C H O H$-Gruppen gegeben sein, die bei der Zuckersynthese verwerthet werden, so dass auch das Verhältniss des synthetisch gebildeten Zuckers zum Stickstoff grösser sein könnte als 2,15.

Jedenfalls geht nicht nur aus meinen Beobachtungen, sondern auch aus den Erfahrungen anderer Autoren (Lüthje; Embden und Salomon u. A.) hervor, dass für das Verbältniss der maximalen Menge des beim schwersten Pankreasdiabetes im Organismus gebildeten Zuckers zum Stickstoffe die von mir gefundene Zahl 2,8 dem richtigen Werte näher kommt, als der von Pflü ge r'gefundene Quotient 2,2, Die Differenz wird, wie oben ausgeführt, zum Teil dadurch zu erklären sein, dass bei den Totalexstirpationen die: Zuckerbildung, im Organismus in Folge der complieirenden Erkrankưngen nicht immer das Maximum erreichte, zum Theil dadurch, dass bei dem nach der Partialexstirpation auftretenden Diabetes die Function des Pankreas nicht vollständig ausgeschaltet war. -

Die Möglichkeit, dass die im Harne erscheinende Știckstoffmenge 
nicht als Maass für die Menge der im Organismus zersetzten Eiweisssubstanzen anzusehen ist, dass durch partiellen $\mathrm{Abbau}$ der Eiwe issmoleküle die für die Zuckersynthese nothwendigen Atomgruppen geliefert werden, und somit eine viel grössere Menge von Eiweissmolekülen sich an der Zuckerbildung betheiligen könnte, als es dem Stickstoffgehalt des Harnes entsprechen würde, ist hier zunächst gar nicht weiter berücksichtigt. In Anbetracht der beim Pankreasdiabetes, wenigstens zu gewissen Zeiten, hervortretenden gesetzmässigen Beziehungen zwischen der Stickstoff- und Zuckerausscheidung würde die Annahme eines solchen partiellen Abbaus der Eiweisssubstanzen nur eine unwesentliche Modification der hier angestellten Betrachtungen bedingen. Man müsste eben voraussetzen, dass in jenen Perioden der Constanz des Quotienten $D: N$, sei es mit der Abspaltung der zur Zuckerbildung verwendeten stickstofffreien Atomgruppen, sei es mit den Vorgängen bei der synthetischen Zuckerbildung, auch eine in bestimmtem Verhältnisse von Statten gehende Abspaltung von stickstoffhaltigen Atomgruppen verbunden ist.

An und für sich möchte ich die Möglichkeit eines partiellen Abbaus der Eiweissmoleküle nach den Untersuchungen von Friedrich $\mathrm{Kraus}^{1}$ ), Umber, Hesse durchaus nicht von der Hand weisen, und es mag dahingestellt bleiben, wie weit man eine solche Annahme zur Erklärung jener Fälle heranziehen will, in denen bei schwerem Diabetes der Quotient $D: N$ noch grösser wird, als er bei der höchsten Intensität des Pankreasdiabetes zu sein pflegt. Pflùge $r$ hebt allerdings hervor, dass er bei der Analyse der Muskeln nach langdauerndem Pankreasdiabetes einen normalen Stickstoffgehalt in der Trockensubstanz der Muskeln gefunden hat (Glykogen S. 497). Er meint, "also fallen die Theorien des Diabetes, welche eine Denaturirung der Eiweissstoffe der Gewebe annehmen". Dem gegenüber darf vielleicht darauf hingewiesen werden, dass, wie schon Umber ${ }^{2}$ ) gezeigt hat, unter einem gleichbleibenden Verhältniss von Kohlenstoff zu Stickstoff sich doch eine partielle Abartung des Eiweisses verbergen kann, die wir nur durch quantitative Analyse der Bruchstücke ermitteln können. Denn unter den in den Eiweisssubstanzen enthaltenen abspaltbaren stickstoffhaltigen Atomgruppen,

1) Deutsche medic. Wochenschr. 1903 Nr. 14.

2) Berl. klin. Wochenschr. $1903 \mathrm{Nr} .39$. 
vor Allem schon unter den verschiedenen Aminosäuren, gibt es solehe, in welchen der Quotient $C: N$ zum Theil weit kleiner, zum Theil weit grösser ist als im ganzen Eiweissmolekül. Es können sich daher die verschiedenen Eiweisskerne in ganz verschiedenen quantitativen Verhältnissen mit einander zu Komplexen vereinigen, die dann ihrerseits wieder einen ungefähr gleichwerthigen Quotienten $C: N$ aufweisen können. Eine sichere Entscheidung dieser Frage würde sich also erst durch eine genauere quantitative Analyse der Zersetzungsprodukte der Eiweisssubstanzen aus den Organen der diabetischen Thiere ermöglichen lassen. -

Wie nun aber eigentlich die Glykosurie nach der Pankreasexstirpation zu Stande kommt, warum nach dieser Operation der im Organismus gebildete Zucker, ebenso wie der in der Nahrung eingeführte, im Harne zur Ausscheidung gelangt, das ist eine Frage, für die einstweilen eine befriedigende Antwort noch überhaupt nicht in Aussicht steht. Indessen darf man, wie mir scheint, ohne Bedenken sagen, dass der diabetische Organismus den Zucker nicht in normaler Weise zu verwerthen vermag. Wenn über die Berechtigung einer solchen Behauptung noch gestritten wird, so ist es eigentlich auch nur ein Streit um Worte!

Sehen wir von der hier nicht zur Discussion stehenden Frage nach dem sogenannten "renalen" Diabetes ab, so wird, sobald man von der unmittelbaren Ursache des Diabetes spricht, immer die Alternative aufgestellt: Ueberproduktion von Zucker oder gestörter Verbrauch des Zuckers. Ist das wirklich ein unüberbrückbarer Gegensatz? Schliesst denn das Eine das Andere aus?

Ich halte es nach dem, was ich oben ausgeführt habe, für sehr wahrscheinlich, dass im Organismus des Diabetischen eine Ueberproduction von Zucker stattfindet, d. h. dass, wenn der Diabetes seine höchste Intensität erreicht, auch das Maximum dessen an Zucker producirt wird, was der Organismus überhaupt zu produciren vermag. Aber diese Ueberproduction ist wahrscheinlich nur eine Folge des gestörten Verbrauchs, sie kann nur die Glykosurie steigern, aber nicht ihre Ursache sein. Wie soll denn allein eine Ueberproduction von Zucker. ohne Störung des Verbrauchs zu einem dacernden Diabetes von der Intensität des Pankreasdiabetes führen? 
Man kann sich allenfalls vorstellen, dass es durch eine plötzliche Ausschüttung des im Organismus angehäuften Glykogenvorraths zu einer Ueberschwemmung des Organismus mit Zucker kommen kann, so dass ein Theil davon in den Harn übergeht. So mag man vielleicht z. B. die Zuckerstichglykosurie erklären, obgleich es auch denkbar wäre, dass auch bei dieser Glykosurie eine Störung des Zuckerverbrauchs mit im Spiele ist. Wie man aber eine dauernde und intensive Glykosurie, die selbst nach Erschöpfung des Glykogenvorraths und bei Ausschluss von Koblehydraten aus der Nabrung auftritt, ohne eine Störung des Verbrauchs sich erklären könnte, vermag ich mir, offen gestanden, überhaupt nicht vorzustellen. Das wäre doch nur denkbar, wenn man von der Ansicht ausginge, dass der Zucker normaler Weise überhaupt nicht im Organismus verbraucht wird.

Suchen wir uns das an einem Beispiel klar zu machen: P fl ü ger berechnet, dass sein Hund, der nach der Partialexstirpation des Pankreas in der Zeit vom 24. December 1904 bis 26. Februar $1905 \mathrm{im}$ Ganzen 3097,1 g Traubenzucker ausgeschieden hat, in dieser Zeit 2499,1 g Zucker aus seinem Körperfett gebildet haben konnte. Das macht also bei 64 Tagen an jedem Tag $39 \mathrm{~g}$, oder, da es sich doch um einen continuirlich vor sich gehenden Prozess handelt, in jeder Stunde $1,6 \mathrm{~g}$. Nehmen wir nun an, der Hund hätte diese ganze Menge nicht gebildet, wenn er nicht diabetisch gewesen wäre, dass also die ganze Menge ihre Entstehung einer „Ueberproduktion" verdankt. Würde nun ein Hund, dessen Zuckerverbrauch nicht gestört ist, wenn man ihm zu einer kohlehydratfreien Nahrung stündlich $1,6 \mathrm{~g}$ Zucker zufügte, diese Menge im Harne ausscheiden? Und dabei nimmt doch Pflüger sogar an, dass die Umwandlung der Fette in Zucker den normalen Modus ihrer Verwerthung darstellt! Man kann wohl darüber streiten, was man unter "Verbrauch" des Zuckers zu verstehen hat, ob man eine Umwandlung in Glykogen, eine Aufnahme in das Protoplasmamolekül, eine Ueberführung in Fett, eine directe Oxydation oder einen vorhergehenden fermentativen Zerfall als den normalen Modus der Zuckerverwerthung anzusehen hat - in keinem Falle aber kommen wir um die Annahme berum, dass die Verwerthung des Zuckers beim Pankreasdiabetes gestört ist!

In welcher Weise allerdings das Pankreas im normalen Organismus den Zuckerverbrauch vermittelt, darüber wissen wir vorläufig noch nichts Bestimmtes. Ich habe in meinen Untersuchungen in 
Bezug auf die Wirkung des Pankreas beim Zuckerstoffwechsel einige Vermuthungen geäussert, die ich auch heute noch für discutabel halten möchte. Ich wies darauf hin, dass die Annahme einer nach innen gerichteten Secretion eines "glykolytischen" Fermentes nicht die einzige Möglichkeit einer Erklärung der Pankreasfunction bietet. Ich meinte: „Es könnte das Pankreas auch in irgend einer Weise auf die Organe einwirken, welche in der Norm den Zucker verbrauchen, z. B., indem es daselbst Affinitäten frei macht, an welche sich das Zuckermolekül anlagern kann. Es wäre auch denkbar, dass der Zucker in der Norm in irgendeiner lockeren Bindung circulirt, welche denselben für die oxydativen Prozesse unangreifbar macht, und dass das Pankreas berufen ist, diese Bindung zu lösen und hierdurch die normale Oxydation des Zuckers zu ermöglichen." Man könnte sich gewiss auch noch manche andere Möglichkeiten denken, aber vorläufig fehlen uns alle Handhaben, die uns ein sicheres Urtheil über diese gewähren könnten. In der Einschätzung aller Versuche über die "Glykolyse" in vitro stimme ich mit Pflüger ganz überein.

Pflüger bekämpft nun auch die ganze Lehre von der „inneren Secretion" der Drüse. Er setzt dieser Lehre die Theorie der „Nervenreizung" entgegen. Es liesse sich vielleicht einiges gegen seine Argumente sagen, aber wer will leugnen, dass beide Theorien in diesem Augenblicke nur Hypothesen sind? Es ist vielleicht nur Sache der persönlichen Neigung, welcher Hypothese man huldigen will. Vielleicht sind beide nicht zutreffend. Dann wird wohl der Vorrang derjenigen gebühren, die den grössten heuristischen Werth besitzen wird, und das muss die Zukunft lehren!

Indem ich mich am Schlusse meiner Arbeit im Jahre 1893 gegen die ursprüngliche Lépine'sche Lehre von der Glykolyse im Blute wandte, meinte ich: "Ueberhaupt ist es vor der Hand noch nicht möglich eine befriedigende Theorie für die Genese des Pankreasdiabetes zu geben ${ }^{\prime}$. Das ist leider auch heute noch wahr! Und wenn Pflüger seine Ausführungen mit dem Ausdruck seiner Ueberzeugung schliesst, dass „keine der bis jetzt vorgelegten Hypothesen mit hinreichender Sicherheit bewiesen ist", und wenn er hinzufügt, "trotz der riesigen Arbeit, welche von vielen Forschern auf diese Frage verwandt worden ist, bleibt der Pankreasdiabetes ein nicht entschleiertes Geheimniss", so befinden wir uns auch hier in einer bemerkenswerthen Uebereinstimmung. Ich bedaure es sicher nicht 
weniger als $\mathrm{Pfl}$ üg er selbst, dass auch s e in e Untersuchungen nur Bestätigungen und allenfalls sicherere Beweise für bereits bekannte Thatsachen, aber keine neuen Ergebnisse beigebracht haben, die zur Entschleierung dieses Geheimnisses dienen könnten!

Aber ist denn der Werth einer wissenschaftlichen Thatsache deshalb geringer, weil uns jeder Fortschritt auf dem Wege der Erkenntniss vor neue Räthsel stellt?

Wir haben bier gesehen, dass die Beobachtungen über den Pankreasdiabetes bereits dazu gedient haben, das Stattfinden einer Zuckerbildung im Organismus sicher festzustellen, und gewisse Bedingungen kennen zu lehren, von denen diese Zuckerbildung abhängig ist. Zur Zeit bin ich mit Untersuchungen beschäftigt, die, wie ich hoffe, in dieser Frage einige weitere Aufschlüsse bringen dürften, über die ich aber nicht früher berichten möchte, als bis die Ergebnisse vollkommen sicher gestellt sein werden. Diese Untersuchungen beziehen sich namentlich auf den Einfluss von Muskelarbeit und Wärmearbeit auf die Zucker- und Stickstoffausscheidung nach der Pankreasexstirpation. Das durch P flü g er's Einwände neu erweckte Interesse für den experimentellen Pankreasdiabetes wird sicher auch andere Forscher zur Bearbeitung der aufgeworfenen Fragen anregen. So unerfreulich daher auch jede persönliche Polemik in wissensehaftlichen Fragen sein mag - in diesem Falle wird sie sich hoffentlich für den Fortschritt der Erkenntniss als fruchtbringend erweisen! 